\title{
Jimmy Choos vs. Ariats: The presentation of masculinity in the online sex ads of men who have sex with men
}

\author{
Adam Thomas Babich \\ West Virginia University
}

Follow this and additional works at: https://researchrepository.wvu.edu/etd

\section{Recommended Citation}

Babich, Adam Thomas, "Jimmy Choos vs. Ariats: The presentation of masculinity in the online sex ads of men who have sex with men" (2010). Graduate Theses, Dissertations, and Problem Reports. 716.

https://researchrepository.wvu.edu/etd/716

This Thesis is protected by copyright and/or related rights. It has been brought to you by the The Research Repository @ WVU with permission from the rights-holder(s). You are free to use this Thesis in any way that is permitted by the copyright and related rights legislation that applies to your use. For other uses you must obtain permission from the rights-holder(s) directly, unless additional rights are indicated by a Creative Commons license in the record and/ or on the work itself. This Thesis has been accepted for inclusion in WVU Graduate Theses, Dissertations, and Problem Reports collection by an authorized administrator of The Research Repository @ WVU. For more information, please contact researchrepository@mail.wvu.edu. 
Jimmy Choos vs. Ariats: The Presentation of Masculinity in the Online Sex Ads of Men who Have Sex with Men

\author{
Adam Thomas Babich
}

Thesis submitted to the Eberly College of Arts and Sciences at West Virginia University in partial fulfillment of the requirements for the degree of

\author{
Master of Arts in Sociology \\ Karen Weiss, Ph.D., Chair \\ Melissa Latimer, Ph. D. \\ Daniel Renfrew, Ph. D. \\ Department of Sociology and Anthropology \\ Morgantown, WV \\ 2010
}

Keywords: gay men, male sexuality, masculinity, presentation of self 


\section{Abstract \\ Jimmy Choos vs. Ariats: The Presentation of Masculinity in the Online Sex Ads of Men who Have Sex with Men}

Adam Thomas Babich

The concept of masculinity should be understood in terms of its fluidity. One cannot say that there is a specific "white" masculinity or a specific "straight" masculinity; rather, masculinity is constantly changing. The inherent problem of defining masculinity has not deterred researches but has fueled a large and growing body of literature dedicated to studying masculinity's dynamic process of change. For a long time, gay men have been regarded as a group who is incapable of possessing masculinity; indeed according to hegemonic masculinity, gay men must be excluded. However, research has shown that gay men are rejecting this notion and are actively engaged in the creation and synthesis of their own versions of masculinity. This study will examine how a group of gay men are portraying, negotiating, or rejecting aspects of the dominant (hegemonic) masculinity in their personal ads on an online website, ManHunt.net. My examination will use both a qualitative and quantitative approach to investigate how these men differ in their presentation of masculinity along with how the age and location of the men affect the prevalence of the traits seen in the online ads. 


\section{Acknowledgements}

I would like to thank my committee for their help and guidance over the past two years. In particular, I would like to thank my chair, Dr. Karen Weiss, for her energy and insight into a project that has evolved greatly since its inception. I would like to thank my close friends who endured long and thought-provoking conversations about new directions the project could take. Finally, I would like to thank my mother and father for their belief in me and their encouragement to finish this study. 


\section{$\underline{\text { Table of Contents }}$}

Chapter 1: Introduction 1

Chapter 2: What's the Masculine in Masculinity? $\quad 6$

Chapter 3: Masculinity and Gay Sexuality 16

$\begin{array}{ll}\text { Chapter 4: Selling Yourself Online } & 27\end{array}$

$\begin{array}{ll}\text { Chapter 5: Methods } & 32\end{array}$

Chapter 6: Findings: Details of the Dudes 41

Chapter 7: Conclusion: Reaching the End of the Rainbow 65

$\begin{array}{ll}\text { References } & 73\end{array}$

$\begin{array}{ll}\text { Appendix A } & 78\end{array}$

$\begin{array}{ll}\text { Appendix B } & 79\end{array}$

$\begin{array}{lr}\text { Appendix C } & 80\end{array}$ 


\section{Chapter 1: Introduction}

As society has become less socially conservative, topics such as homosexuality that were once spoken of in a hushed whisper or avoided all together are now commonplace. The topic of homosexuality is now more than ever seen throughout the media, such as in Ang Lee's (2005) Brokeback Mountain, which told the story of a love affair that continued for years between two cowboys. Television shows such as NBC's (1998) Will \& Grace and Showtime's (2000) Queer as Folk not only depicted the lives of gay men and women for a wide audience, but also managed to win several media awards. Even politically, homosexuals have been gaining momentum as seen with the recent equality marches, passing of legislation that includes sexual orientation in hate crime law, and the recent changes several states have made by legalizing gay marriage. Although it appears society has begun to accept homosexuality, arguably some more reluctantly than others, there is still a general disdain for homosexuality which I believe can be summed up in one word: faggot.

"Faggot" is a derogatory term used to refer to a homosexual male, though its original meaning was a bundle of sticks. It is not important for my research as to how the word became to denote a man who adores other men; rather, what is of concern are the reasons as to why words such as "faggot" are considered an insult whether the unfortunate recipient is either homosexual or heterosexual. Why is it considered an insult to be called a "queer" or "sissy" if one is male? Why does society feel that for two men expressing love towards one another is such a travesty that warrants verbal and sometimes physical attack? Is it the specific act of two men engaging in these behaviors what provokes fear and anger in others, or is it what the behaviors symbolize?

Although feminism has gained much headway in recent years, society still holds many patriarchal views. Often times we can see this in certain phrases, such as "fight like a man," "be 
a man about this," and "man up." Sayings such as these give the impression that to be a man is to be tough, and to be tough is to be a man. It is with this impression, this idea that masculinity is the dominant force in society that my research focuses on. When someone refers to a man as a "faggot," they are not focusing on the man's sexual preference, but are focusing on robbing that man of what seems to be his most prized possession: his masculinity. Since "faggot" is often synonymous with gay, it stands to reason that in the eyes of those brandishing the word, to be gay is to be less of a man. In the literature review that follows I will present research that shows how masculinity is defined and created in society along with research on how gay men are defining their sexuality. In accordance with what the literature has found, I expect to find that the gay men in this study are engaged in a negotiation of masculinity. This negotiation refers to the process where the gay men in the study take what is ascribed by the dominant masculinity (e.g. being dominant) and alters or manipulates the definition to accommodate their behaviors (e.g. being sexually submissive) and sexuality.

Masculinity is not a set definition, but a living and changing entity, responding to the social pressures exerted by members of the culture. It is no surprise that any form of masculinityworking class, white, hegemonic, gay- can vary between cultures and even within that culture during various times in history or even at different times of the day (Kimmel 2008). One must keep in mind that these forms of masculinities should not lend to an oversimplification of seeing a definitive black masculinity, or a definitive working class masculinity (Connell 1995).

Men detest the thought of being seen as weak to their male counterparts (Kimmel 1994). These individuals will use several tactics, including violence and the subordination of women, to work their way up the male social ladder towards the ultimate goal of the hegemonic masculinity. However, some men only chose certain parts of the hegemonic to ascribe: the 
individual may strive for power in the business world but hold the idea of sexism and misogyny in contempt (Connell 1995). Gay masculinity is constructed with hegemonic masculinity as a blueprint. It is impossible for a gay male to follow hegemonic masculinity to the $\mathrm{T}$, since by definition the act of having sex with another male excludes the individual from the dominant group. However, gay men have realized this and are tailoring their fabrication of masculinities to meet their culture's needs.

This study looks at how gay men are constructing a masculinity which uses the hegemonic masculinity as a scaffold. After reviewing what the literature has found on masculinity and gay sexuality, this study will use grounded theory and content analysis to investigate what aspects of masculinity these men are including in their online personal ads. We begin with the second chapter which explores what the literature has found on masculinity in society. An examination of various studies will lay the foundation for how masculinity exists in our culture and what is expected of men if they are to embody this masculinity. The third chapter will begin to explore the phenomenon of sexuality, focusing specifically on gay male sexuality towards the end of the chapter. Here we will discover the practices within the realm of sexuality, and how gay men are tailoring these practices to coincide with the ascribed traits of the hegemonic masculinity. Chapter four will shift to a discussion of the online realm and how individuals are portraying themselves online in order to appear desirable to potential partners. Literature in this section will look at how individuals, more specifically gay men, are including certain types of information in their online profiles to generate a more appealing image of themselves.

By then we will have reviewed the literature enough to move onto the methods of the study. Here I will lay out in detail the methods I used, both in data collection and data analysis, 
to examine the 480 profiles from the website under study. The chapter on the findings will explain both the quantitative and qualitative data. The quantitative data will show how the various traits of masculinity were portrayed in the profiles, both in simple percentages as well as how the traits varied across the age groups of the individuals as well as how they varied based upon the individual's location in a rural or urban setting. Finally, the concluding chapter will describe how the results of the study fit into the larger picture of masculinity and sexuality, and describe how the gay men in the study are engaged in a negotiation with their sexuality and what is ascribed by the dominant masculinity.

The first objective of this study is to see how men on ManHunt.net, a popular gay cruising website, are presenting themselves in accordance with what is ascribed by hegemonic masculinity. Using an inductive grounded theory approach, I will examine the narratives of nearly 500 profiles from the website, searching for evidence of this negotiation of masculinity. Through content analysis I plan to discover what traits are important to these men, and if these traits coincide with what the literature says about masculinity, or if the traits embody something else. The data will be explored both qualitatively as well as quantitatively. Focusing on the idea of actual executions of behaviors of masculinity, I believe that the men in the online community are capable of executing both feminine and masculine traits simultaneously. To further explain this, I believe that the men in my study will portray both the traits expected of a masculine heterosexual man as well as the traits expected of those ascribing to a more feminine persona.

The second and third objective sought to determine how the prevalence of these traits differed across age groups and across rural and urban locations. The literature has shown that a preoccupation with youth exists in the gay community (Barker 2004, Goltz 2007). Due to this I had reasoned that men of different ages may place more emphasis on different aspects of their 
profile. Research has also documented the effect of rural and urban locations on the gay

community (Preston, D’Augelli, Kassab, Cain, Schulze, and Starks 2004), where rural areas tend to be more conservative than urban areas, and as a result may affect the way gay men present themselves. 


\section{Chapter 2: What's the "Masculine" in Masculinity?}

In the course of conversations at a local gay bar, the topic of the "ideal" man came up. While the group I was with generated several "important" qualities, "masculine" or "butch" was a reoccurring characteristic that my friends believed the perfect man would possess. As we broke from the conversation to sip our beers or take drags from our smoldering cigarettes, I began to ponder what masculine could mean, and if it differed from person to person. Looking around the bar, I noticed a particular individual who, despite the rather frigid October temperatures, was shirtless. His upper body, which hinted at several hours a week spent at the gym, was mildly hairy and branded with a dark tattoo on his left arm. He was an older gentleman; his jaw was outlined in a thin manicured beard. Initially, I held the impression that this man, in his rugged appeal, would fit the definition of masculinity. That was, until he began to speak. His voice was tinged with the cliché gay lisp and while the conversation he was engaged in appeared to be as casual as the one my friends and I were having moments before, his hands moved in exaggerated motions.

Though I had encountered men like this before, I began to ponder the depth of the disparity between the man's rugged appeal and his apparent "effeminate" speaking traits. While it was only speculation, I wondered if the man considered himself as masculine. It seems arbitrary, pointless, and perhaps stereotypical to place labels on people such as "butch" or "feminine" but people in general still use labels and categories. In order to label something a general set of qualifications has to exist to warrant inclusion in a particular category. As the saying goes "If it walks like a duck, quacks like a duck, looks like a duck, it must be a duck." So we must ask ourselves, what are the qualifications one must possess in order to brandish the label of masculine by society's view? Assuming this all-inclusive list exists, which the following 
review of literature will show is definitely not the case, who then decides what goes in and what is excluded from the definition of masculine? In order to answer these questions, we must look at the politics that surround the creation of this "holy grail" of masculinity. By politics, I am not referring to the men and women on Capitol Hill, but rather the negotiations that arise within a culture during the formation of phenomena such as masculinity. Past research on the position of men in sexual politics (for example, see Tolson 1977; Lewis 1983) has lead to the huge field of descriptive research known as "masculinity" studies in the United States (Brod 1987; Kimmel 1987.)

So what exactly is masculinity? Some studies have suggested masculinity in its truest form can only be created among other men and requires a push for men to withdraw psychologically from the feminine (Bly 1990; Keen 1991). We may have heard of young boys being taunted if they appear to their male companions as a "mama's boy." If a man appears to be under "the control" of his girlfriend he may experience the taunt of "being whipped". These are both examples of how men can be perceived as less masculine because of an attachment to the other sex. An additional view on how men produce masculinity is offered from a combination of the psychoanalytic discourse on homosexuality and Chodorow's (1978) psychoanalytic and sociological theory. In this theory, she posits that masculinity is influenced by the boy's and men's relations to women, particularly with their mothers. The male learns two things from the mother: masculinity is superior but less available and that the mother is regressive and lacking autonomy. Therefore, the only way the young male can develop his masculinity is to deny identification and attachment to the mother. However, Connell (1992) stresses that these relations should not be seen as deterministic. In his study of eight life cases (1992), Connell found that the family setting is an important arena where gender relations are negotiated. From 
the interviews, he found that a conventional structure of a patriarchal household boasts a range of possibilities than can affect emotional relations in the fabrication of gender.

I believe one of the central ideas to fully understand this thesis and the research that surrounds it is the recognition of modern epistemology that description cannot exist without a reference point (Connell 1995). In order to describe what constitutes masculinity, we must have something (femininity) to define it against. Rather than define masculinity as an object, it should be characterized by the processes through which men and women perform gendered lives (Connell 1995). I proffer the definition of gender (Butler 1999) as the performance of feminine and/or masculine traits trough repetition and throughout the individual's life. Defining gender is not easy. Many scholars and philosophers, from Aristotle to Judith Butler, have provided their critiques on this well heard of, but often understood subject. I will start by pointing out that there exists a difference between gender and sex; the second part of this chapter will focus on the later. In its most basic sense we can see that sex is comprised of the biology of the body, where gender pertains to the cultural and social regulations of that sexualized body. Colebrook (2004) argues that we may view gender as a social construct, or that gender may exist in order to differentiate between the real and ideal; the only way that these two concepts become available to thought is by treating them as gendered metaphors.

This abstract and philosophical critique may be difficult for the average thinker to grasp. Colebrook (2004) argues that the idea of masculine and feminine exists to understand opposing forces, as he argued in the metaphor of light penetrating the darkness. The light, a dominant and active role, penetrates the passive and receptive darkness. This is his interpretation and others of course may have a different perspective. What is important is that from his metaphor we can see that he feels that one gender should be active while the other passive. Perhaps you have already 
begun to see the parallel between the act of the forces and the act of the male during sexual intercourse. I believe that this is how we should look at gender to understand the purpose and rationale for this study: that one way gender can exist is in the form of power, or opposing forces. Minimal binary is necessary because in order to assert that something is, we have to be able to assert what it is not (Colebrook 2004). It is for this reason that D'Emilio (1983), among others, has argued that "homosexuality" as a category of people has not existed through time but was created through cultural development, most notably capitalism. If heteronormativity (the belief that heterosexuality is the norm) did not exist, then homosexuality could not exist.

I stress to the reader that the use of 'masculine' and 'feminine' in my discussion on gender does not relate entirely to the idea of a man or a women. Rather, when using the terms masculine and feminine, I use them to illustrate the point of power and dominance. Butler (1999) argues that gender exists as a production of masculine and feminine traits that are ritualized and repeated often. This is an interesting statement. If we say that a man is exhibiting feminine traits, we are not focusing exclusively on the actions themselves, but how the actions are perceived in society. I believe that this also occurs in the society of men in their creation of 'gendered masculinities.' Under this ideology men could assume two possible stances if you will: one as an active, penetrating agent or the other as a passive and receptive one, with the second type being viewed as devalued and excluded from being an ideal citizen (Parker 2001). This presents a problem for gay men because gender identity is a production of the negation and distancing of one gender from other; however, the gay male body has to enable the same body to be both masterful and submissive (Bersani 1995).

I mentioned earlier the idea of politics as negotiations and relationships among individuals in a culture; it is these politics that essentially are responsible for the type of gender 
that is created by the individual. Connell (1995) devised a three-fold model of the structure of gender: power relations (the dominance of men and the subordination of women), production relations (gendered divisions of labor) and cathexis (whether pleasure is reciprocated during sexual relations). It is these relationships within gender that ultimately govern social practices and beliefs, such as race and class. With these relationships, as with most, there exist inequalities. For example, a glimpse of the U.S. Senate shows that the majority of the ones in power are white, wealthy, men.

With multiple interactions between class, race, and gender, we also have multiple masculinities. Connell (1995) was quick to point out that there exist problems with the idea of multiple masculinities. When looking at the relationships between the masculinities, one should not assume there is a particular black masculinity or a particular white masculinity; a particular working-class masculinity or particular middle-class masculinity. A second problem, most often seen in cultures that focus on individualism (the United States, for example) is that if one recognizes the existence of multiple masculinities, they may begin to treat them as alternative choices. An appropriate example here is when gay men are believed to be consumers of an alternative lifestyle; that heterosexuality is the norm and gays are deviants.

Connell's (1995) study of Australian men who centered their lives on the saying "live fast and die young" began to expose the possible forms of masculinity. Masculinity is a collective practice; the actions performed within the group may have no bearing or meaning outside that social situation. While one of the men owned a motor bike and sported tattoos and earrings, he realized that on his own, this appearance would do little for him. Focusing on the level of personality, Connell (1995) used examples from his research to substantiate what Alfred Adler (1928) termed "protest masculinity." This pattern of behavior was the result of feeling powerless 
during childhood, leading to an overzealous claim to the Euro/American definition of masculinity. Instances of this type of behavior, according to Connell's study, involved wild rides in a motorbike gang and the practice of physical and verbal attacks on homosexuals.

There are four relations among masculinities identified by Connell (1995): hegemony, subordination, complicity, and marginalization. "Hegemony" refers to the dynamic where a group claims and sustains a leading position in social life. Since different groups have claimed leadership at different times throughout society's history, so does masculinity. Hegemonic masculinity is the current gender practice that epitomizes the guarantee that men are in the dominant position and women are subordinate (Connell 1995). The word "current" in the above statement is important, because what embodies hegemonic masculinity can change throughout time and throughout various cultures. For example, the New Guinean society exhibits same-sex relations as a way for the young male to achieve masculinity and reach adulthood (Herdt 1997) (refer to Chapter 2 for further discussion of this example). This stands in stark contrast to the hegemonic masculinity seen in Western societies since the practice of same-sex relations works to exclude the individual from the dominant masculinity. If a group or individual is to hold a position of power, by definition they must be holding power over someone. A prime example for American/European society is the subordination of homosexual men by heterosexual men. Altman (1972) described the various ways gays are shoved towards the bottom of the male hierarchy: political and cultural exclusion, street and legal violence, and cultural abuse. Other variations from the hegemonic masculinity are also subordinated and most (sissy, pussy, weak) are closely associated with gayness, and by a larger extension, femininity. Complicity refers to the relation of complicity with the hegemonic masculinity. Although the hegemonic masculinity is held at the top, very few men actually embody this; however, through complicity men can 
benefit through at least some connection to the hegemony. Finally, marginalization refers to the relationships among the masculinities in the dominant and subordinated cultures (Connell 1995). What is being argued is that between the masculinities, competition is present, and for the hegemonic masculinity to remain at the top, other forms of masculinity that threaten to usurp the dominant post must be marginalized, or pushed to the sidelines.

\section{Key Components of Hegemonic Masculinity}

At this point, I would like to introduce what I believe to be the key components of hegemonic masculinity that studies have shown are of great importance to men. The order in which I introduce the component does not indicate importance of one over the other. The first component of hegemonic masculinity is sexual promiscuity. Promiscuity is strongly associated with manhood and masculinity (Duck 2009), a concept that is generally understood throughout popular culture. The theme for the movie American Pie (1999) centered on a small group of friends who felt that in order to become "real men" they needed to lose their virginity. In Kimmel's book Guyland (2008), he also comments on the need for sexual conquests to validate masculinity. One male reported that the first thing he thinks about after getting laid is telling his friends. Men are in constant competition with each other, and it is clear that sexual promiscuity is just one way to fight for masculinity. The second component is risk taking. Courtenay (2001) believes that what is considered masculine in the United States may produce self destructive and risk taking behavior; this due to the practice of the rejecting bodily maintenance as a way to achieve hegemonic masculinity (Bunton and Crawshaw 2002). Other studies have shown that men who believe in the ideal masculinity will be more likely to use drugs, alcohol, and tobacco 
(Blazina and Watkins 1996) and engage in risky sexual practices (Pleck, Sonenstein, and Ku 1994).

A third component of hegemonic masculinity is the belief that a true man has an aversion to femininity and homosexuality. As far as hegemonic masculinity is concerned, homosexuality is essentially a negation of true masculinity and the heteronormative ideal. Therefore, another aspect to this component is some men believe that to possess masculinity is to be straight or heterosexual. This creation of heterosexualism is underlined by the argument that antigay attitudes are not just associated with "hierarchic heterosexuality" but is central to it (Brittan 1989). One possibility provided by Brittan (1989) to explain some men's aversion to homosexuality is that 'hierarchic heterosexuals' know that all gender types are fragile and the only way to hold on to the status quo is through coercive means. Thompson and Pleck (1986) found that men answering a questionnaire produced a factor of responses that was classified as an Antifemininity factor. Such questions related to this factor were feelings of disdain for men who acted feminine and a reluctance to choose jobs that were considered to be only for women, such as a secretary.

A strong sense of dominance is the fourth component to hegemonic masculinity, in both the subordination of homosexuals and of women. As mentioned previously, Connell (1995) argues that the hegemonic masculinity asserts the dominant position of men over women. Another facet to the idea of dominance that may not always be addressed is the dominance of heterosexual men over other heterosexual men. This is most apparent in men's constant need to compete. Although not all men engage in competitive behaviors, studies have shown that almost all of them at least understand that masculinity expects some form of competition (Bird 1996). 
The final component is emotional detachment. Masculinity must be fostered by a withdrawal psychologically from women (Bly 1990; Keen 1991), and emotional detachment offers a way for men to be confident and independent, both of which are characteristic of Brannon's (1976; Brannon and Juni 1984) “sturdy oak” cluster of the traditional male norm.

Sociologists have argued that masculinity cannot exist by itself; it must be seen in context of the relationships in which it occurs. For an extensive history of masculinity, see Chapter 8 Masculinities by Connell (1995). Connell has provided examples of crisis tendencies that influenced an increase in or acceleration of masculinity, or a return to the traditional masculinity. The Women's Liberation movement coupled with the loss in Vietnam produced new cults of true masculinity in the United States, including violent adventure movies and an expansive gun culture. Through various social changes, masculinity politics have arisen. Connell (1995) defines "masculinity politics" as the efforts and processes where the meaning of the masculine gender is constantly being evaluated and altered. I believe that for this thesis, the most important form of masculine politics is the gay liberation movement. The reason this is important is because gay men began to rebel against what constraints society had placed upon them. Through this rebellion, gay men began to redefine themselves and what it meant to be a man. Connell believed that the challenge to established power in the 1960's coupled with the association to radical feminism paved the way for the Gay Liberation to mount an all-out offense to hegemonic masculinity. Mieli (1980) argued that the oppression of gays by straight men was a direct result of the repression of femininity in men in an attempt to exact male supremacy. This argument coincides with my earlier statement that the word "faggot" is used as an attack on the presence of feminine qualities in men. The challenge to the gender order did not come as influx of drag queens, but with the arrival of the "clones" of the 1970's- jeans and T-shirt, cropped hair and 
moustaches (Connell 1995). Were the gay men of that time trying to assimilate into the mainstream definition of masculinity, or was this an attempt to mock the current held ideal? As the association with feminism weakened, gays began to move into the public arena of business as well as municipal governments (Connell 1995). Since hegemonic masculinity is synonymous with desires for success and achievement in society through the use of dominance (Duck 2009), it was no surprise that the retaliatory use of dominance by the dominant group was both verbal and physical attacks on the gay population. Connell argued that a gay community in of itself does not create opposition to the masculinity politics, but the mere presence of an unwavering alternative to hegemonic masculinity resulted in the reconstruction of the masculinity politics as a whole.

In the next chapter we will review what the literature has found on the subject of sexuality, and more specifically that of gay sexuality. I have argued in the current chapter that there are several traits that a man must possess in order to obtain or embody the dominant masculinity. In Chapter 3 we will briefly review what the literature has found on same-sex practices in other non-Western cultures. Afterwards we will turn our attention to the same-sex practices of men in the Western world and examine how the sexuality of gay men has its roots in the masculine traits laid out in the current chapter. 


\section{Chapter 3: Masculinity and Gay Sexuality}

You may be wondering about the rationale behind the title for this thesis "Jimmy Choos vs. Ariats." Both are brands of shoes; Jimmy Choos are designer high heels, where Ariats are a brand of cowboy boots. The significance is the symbolism behind the shoes; high heels would be a choice for the "feminine" while cowboy boots would most likely be the choice of the “masculine." By placing these two examples of footwear head to head, I attempted to convey a comical but true relationship that exists in the construction of gay masculinity. Gay men in our society may at times be oppressed, but they are not completely dismissed as being masculine. However, Connell (1992) points out that they face conflicts between their sexuality and their social presence as males, since most of society regards homosexuality as a nullification of masculinity. As gay men become aware of this conflict they begin to formulate how to resolve the disparity. While alternative masculinities exist, it is important to remember that the term alternative should not denote that one masculinity is more socially appropriate over the other. I believe that gay men can chose to create their masculinity so as to closely resemble that of the hegemonic masculinity (the Ariats), fully reject the hegemony (the Jimmy Choos), or develop some variation in between

Guyland (2008) by Michael Kimmel is a compelling read and valuable both to the general populous as well as to the study of masculinities. Kimmel takes the reader into the place where boys become men, Guyland, and focuses on several defining aspects of the guy realm, including sports, pornography, and sex. While the work of Connell is invaluable to the study of masculinities, Kimmel (2008) focuses on the years between 16 and 26 which he argues is the most influential to the creation of masculinity. The book does not focus on how gay boys become gay men, but it lays down an excellent measure for comparison. Whether a guy is 
heterosexual or homosexual, he is still a guy, and as research has shown, society places certain pressures on men. Guyland (2008) directs the reader through different areas of this "mencreating" process, such as high school, binge drinking, media, pornography and sex. I argue that gay men experience these facets as well, but of course, in a slightly different light (the most apparent is that it would be unlikely to have a straight man watching exclusive male-male porn, and vice versa for a gay male with women-women porn). Kimmel (2008), reports that men are informed about the ideas of masculinity from the other men in their lives (coaches, fathers, and brothers). How then do gay men procure their idea of masculinity? Do they obtain the same information that straight men do and somehow try to assimilate or modify it into their identity? While this is possible, it seems unlikely. Gay men no doubt absorb ideas of masculinity from straight male counterparts in their lives, but they also must have an outlet to obtain ideas of masculinity that is more in sync with their sexual orientation. Before we begin our discussion of masculinity for gay men, we must first discuss the concept of sexuality with regards to same-sex relations, beginning with those same-sex relations in non-Western cultures. This will allow us to develop a comparison for how homosexuality is seen in other cultures that do not possess the taboo of man-on-man sex that the Western world does.

It is important to keep in mind that certain traits may result in a perceived gender in one culture and a different perceived gender in another. In ancient culture, one of most frequently mentioned groups to engage in same-sex behavior was the Sacred Band of Thebes (Herdt 1997). Though erotic unions, the warriors created an unshakable courage that, as Plato was concerned, resulted in "An army consisting of lovers and their beloved ones, fighting at each other's side, although a mere handful, would overcome the whole world" (cited in Westermarck 1908, 479). This is an excellent example of the difference in cultural interpretation of same-sex relations 
between the Western world and other societies. These soldiers who had male lovers were not the “sissy" stereotype portrayed in Western culture, but fierce and determined men.

A different view of same-sex practices are held by some New Guinea societies. Herdt (1997) collected evidence on men within the villages and eventually developed a cultural concept he coined as "boy-inseminating rituals." The purpose of this was not primarily pleasure but to "masculinize" the young male by providing him with semen since it was believed that his body was not capable of producing the semen on its own. According to the local cultures, semen was the elixir of life, and required for the creation of masculinity and the fostering of the warrior personality. Typically, the older male is the semen donor, who not only receives pleasure but also passes on the achievement of manhood. Herdt (1997) further elaborates on the rules governing the inseminating rituals by noting that the young males must never reverse the roles with the older males or take younger partners before the proper initiation ritual. Violation of these rules is wrong and results in a variety of punishments for the perpetrator. It is interesting to see that these same-sex exchanges are still governed by rules, as are the same-sex relations in Western culture. At one point in a casual discussion, an individual posed the ideal that sex with a man wouldn't be that bad as long as he was not being penetrated. Although this "norm" is not sanctioned by a group or prescribed a set of punishments, the idea of still maintaining a dominant role which prevents the individual from being classified as gay is still worth nothing. The examples of past same-sex relations and the "boy inseminating rituals" of the New Guinea show that the same physical act can be differently defined by different cultures at different times.

So what does our society say about same-sex relations? Although considerable progress has been made in the acknowledgement and acceptance of gays in society, there still exists the status quo of heternormativity. This status quo refers to the socially held belief that to be 
heterosexual is normal, and to deviate from this norm is frowned upon. The myth about this exists through media and is indoctrinated into us as we are growing up: the attraction to the other sex, the wedding, the fostering of biological children, and watching those children foster children (Herdt 1997). However, even heterosexuals can see the fault in this myth from divorce rates, to being a widowed, and those unable or unwilling to have children. This may produce stress in those individuals, a stress that is arguably higher for gays and lesbians who cannot even manifest the first facet of the myth, that of having relations with the other sex. Minority stress has been related to several negative health factors including the increased risk of contracting HIV (Hamilton and Mahalik 2009). During the AIDS crisis in the 1980's gay role models were difficult to find. Fortunately, with a growing acceptance of homosexuality, more role models have begun to surface, and having someone to identify with can arguably decrease the stress for this group. By creating identity and cohesion in this group, people are better able to included health management in their social world (Herdt 1997).

Recent research has begun focusing on how homosexuality exists in the social/cultural context. During the 1970's when the gay liberation movement was starting to gain momentum, gay men in the media were depicted as effeminate; however, the culture began to adopt hypermasculine qualities that relied on the working class aesthetic (Clarkson 2006). This clone culture (a well known example was that of The Village People) was a challenge, or mocking, from the gay community in response to society's claims that although gay men were not "real" men, they were expected to act like one (Edwards 1994).

The synthesis of gay masculinity in social dynamics was examined in two influential studies: the analysis of the erotic nature of working class bodies (Rofes 1997) and the gay skinhead identities that developed in Britain (Healy 1996). These studies highlighted the idea 
that gay men are adopting a masculinity that seems to centralize around the idea of "just one of the boys." Clarkson (2006) looked at the discourses among gay men on StraightActing.com, a website dedicated to the "straight-acting" gay man and his discussions with other like minded homosexual individuals. Clarkson reviews one web post from a member that describes his idea of a masculine man should consist of "a foul mouth" (p.198), not using deodorant after a shower if they shower at all, messy apartments, tattoos, and "(healed) cut marks on their bodies" (p.199). From this we can see that the individual's ideal partner is one with rough corners, a tough demeanor, and an apparent disregard for general hygiene. Another web post stresses that his ideal partner should have a "rugged/solid build" (p. 199) and that a masculine body does "bodybuilding and power lifting. Not just the pretty stuff but brute strength" (p. 199).

While the idea of gay men creating a masculinity that focuses on working class aesthetics and the "rough and rugged" may be harmless, an aspect of masculinity that gay men have apparently focused on may be a more pressing concern. Kendall (2004) concluded from his study on gay male pornography that the present obsession by gay men with hypermasculinity devalues self-respect and safe sexual practices. Kendall found in his analysis of gay male pornography that the gay male who is more dominant and "straight-acting" is the one who is revered. His study further recounts pornographic themes that revolve around animalistic sex, truck stop sexual encounters, and rape by larger more powerful men. The third notion of rape may seem contradictory since the dominant one is often revered in the pornography (Kendall 2004). However, it may be a type of transference or a way for men to be close to the dominant one even if they themselves are not dominant. A common theme seen in gay pornography focuses on a father/son type relationship of the two men involved, as seen with several pornographic websites such as HungDaddy.com, DadTrySon.com, LustfulDaddy.com, and DadBoyCinema.com. This 
relationship is characterized by one man acting as a pseudo-father, often requiring the other partner to refer to him as "daddy" and to adopt a child's mentality and social presence. This is perhaps another way men seek to illustrate masculinity by creating a dynamic where one man is seen as the patriarch and thus seen as the dominant figure. The results of Kendall's (2004) study on pornography and the several website indicated above coincide with earlier research on the idea of gender as a social hierarchy. Perhaps gay men have adopted this hypermasculine persona as a way to counteract society's beliefs that gay men are seen as less of a true man. By adopting a dominant and sometimes abusive outlook towards sex, the gay individual may be able to overcome this imbalance in social dynamics. Connell (1995) notes that this appears to be counterintuitive; if gay men are attempting to move more towards the hegemonic masculinity, why would they be engaging in receptive anal sex if that is excluded from the definition of hegemonic masculinity. However, simply because one is receptive during sexual intercourse does not automatically mean they are passive, as seen with power bottoms, or those men who receive anally during sex yet control the rhythm and force of the intercourse. My study has found that not all gay men are considered bottoms; some may adopt a strict preference to the top position or they ascribe to a versatile preference, being both a top and a bottom. Either the subordinate partner is choosing to reject the idea of masculinity, or perhaps the individual can reason that his actions are deemed acceptable if he possesses other forms of masculinity.

In a study of the sexual politics of African American males, Duck (2009) discovered a narrative centering on sexual promiscuity that emerged during the analysis of his interviews. Within this narrative, the participants seemed to indicate that sexual activity is an important aspect of masculinity. Duck argued that the participants avoided HIV/AIDS testing because if the individual received a positive result, this would disrupt their ability to have sex. Other studies 
acknowledged by Kimmel and Messner (1989) and Forrester (1986) contend that American men are taught to validate male social status by engaging in high risk activities. While some men may perform risky stunts on a dirt-bike or physically take on a more formidable adversary in a bar fight, some men chose to engage in these behaviors during sex. In one of the narratives the participant reported that if his friend were infected, the friend would prefer to continue engaging in sex until they succumbed to AIDS. It may be important to note here that the men in Duck's study were self-identified heterosexual males. However, since African American males are considered a marginalized group, they will not knowingly do anything that would result in the marginalization of their masculine status, including inviting the possibility they may be perceived as homosexual (Duck 2009).

In support of growing literature, Hamilton and Mahalik (2009) found that masculinity was a significant predictor of the health risks performed by gay men who feel that traditional ideas of masculinity include the engaging in of risky behaviors. This study also found that gay men's fabrication of masculinity appeared to contribute to their substance abuse as well as their sexual risk taking. Kimmel (2008) points out that risk taking is also seen in the construction of heterosexual masculinity with episodes of binge drinking and promiscuous sex. Significant correlations have been found between believing that sexual prowess is a component of masculinity and the intentional practice of unprotected anal sex (Halkitis and Parsons 2003). Another reason that gay men appear to put great emphasis on sexual adventurism was suggested by Halkitis (2001): gay men use their promiscuity as a mechanism to affirm not only their masculinity but also their desirability and health, even if the individual is living with HIV. It now becomes an issue of public health if gay men are intentionally engaging in risky sexual practices as a way to affirm their masculinity. Several studies have mentioned this issue, including one by 
Kendall (2004) which argued that not only does sexual education need to target this specific population, but something as ubiquitous as pornography needs to be examined. He points out that many pornographies depicting gay male sex either do not use condoms or angle the cameras to give the illusion the condom is absent, resulting in the discontinuation of condom use by gay men who view these images.

\section{Aspects of Masculinity Important to Gay Men}

Stemming from what the literature on masculinity revealed, I believe now is the time to elaborate on the aspects of masculinity that appear to be of importance to gay men based upon the previous studies. The first component is risk. Studies have shown that gay men tend to exhibit health risk behaviors, both sexual (such as barebacking) and nonsexual (drinking, smoking and substance abuse (Hamilton and Mahalik 2009). We have also seen that hegemonic masculinity contains elements of risk (Blazina and Watkins 1996; Pleck, Sonenstein and Ku 1994). It appears that gay men are aware of the risk element seen with hegemonic masculinity and have pursued this trait in their creation of masculinity. Since the study is on the profiles from a sex seeking site, I doubt we will find evidence of nonsexual risks (drinking, drug use) but will instead see instances where the individual has focused on the risky aspect of sex.

The second aspect of masculinity created by the gay men in this study is "no strings attached." The NSA mentality refers to the belief held by men who search for sex online that the sex should be without emotional attachment. The NSA mindset of these men can be seen in the literature on heterosexual men attempting to achieve the hegemonic masculinity. One of the clusters of Brannon's “sturdy oak" (1976) requires emotional detachment to achieve confidence and independence (Bly 1990). 
Though sports do not have a direct link to hegemonic masculinity, heterosexuality is often preoccupied with sports, as seen from their competitive nature. I believe that it is not specifically sports that men focus on, but through sports they are able to demonstrate their level of strength. Men are in constant competition with each other, and watching other men compete through sports is just as important. Gay men tend to take an exaggerated stance on sports and physical fitness (Phua, Ciambrone, \& Vazquez 2009) by constantly mention body measurements and their identification with jocks and studs. The fascination and obsession of gay men for the perfect physical physique is another component. Simpson (1994) asserted that body building was originally gay culture, and it wasn't until the 1980's that movies like Commando "butched up" the practice of body building. While he further argues that straight body building became a natural way to reassert men's superiority for women, Long (1997) believed that the goal of the gay body builder was purely aesthetic- to look good during sex. Lastly, gay men have exaggerated the idea of rugged masculinity through the "bear culture." This culture is defined both by physical attributes (stock build, amount of facial hair) and mental traits (down-to-earth, easy going, independence, masculinity) (Hennen 2005). I believe this culture takes the concept of the rugged lumberjack or steel worker of the heterosexual realm and creates an entire identity and lifestyle around it. A participant in Hennen's study summed it up best by saying that bears are normal, regular guys that happen to be gay.

Finally there are two new components that are not necessarily part of the hegemonic masculinity, but are of importance to gay men. Safe sex and the individual's HIV status is often a topic for gay men, given the problem of HIV/AIDS that the culture experiences. Often advertisements stress that not only is the advertiser "clean" but will only accept partners that are "clean" as well (Phua et al. 2009). Another application to this concern with health may also be 
understood by the men who are identify as heterosexual yet practice same-sex sex; if the individual contracts an STD, he may be viewed as homosexual or at the very least his cheating (if that is the case) could be exposed. Finally, the preoccupation with youth is well documented within the gay community (Goltz 2007). Barker (2004) and Hostetler (2004) found that within gay culture, the marker for being "old" or "older" can begin at age 35 to 40 . This notion is seen throughout popular culture and gay youth discourse (Hostetler 2004) where gay men may fear getting older. While the generation gap or daddy/son relationships are found within the gay community, age is evaluated more strictly than for heterosexuals (Goltz 2007). Age may not just be an evaluative characteristic for gay men but also affect how men are engaging in sexual behaviors. This may be in large part because older gay males experienced the AIDS crisis of the 1980's first hand while younger gay men have not.

There exist several similarities between what is considered to be a part of Guyland and what is a part of "Gayland" or the construction of gay masculinity. Both appear focused on emotional detachment, risk, while gay men appear to additionally focus on vitality and strength. The concept of strength, while not covered in the masculinity chapter, does derive from what society has labeled as masculine. Some differences between hegemonic masculinity and gay masculinity do exist, for example, the practice of being anally penetrated during sex is in stark contrast to the heteronormative masculinity yet it appears that some gay men do not see this as an "unmasculine" act.

By this point we have laid the foundation to understand how masculinity is perceived and evaluated in our society and how gay men are tailoring their sexuality to reflect the traits of this dominant masculinity. We have seen that while traditional masculinity initially excludes gay men from possessing masculinity, gay men have rejected this notion and appear to consider 
themselves very masculine as seen with their sexuality. The next chapter will look at the online community where the study itself takes places. We will review what the literature says about creating online advertisements and how individuals are tailoring the creation of their profile to reflect the most desirable traits. Since I have argued that masculinity is desirable for gay men, the profiles under examination will be created to maximize the individual's traits that most closely reflect the ideals of traditional masculinity. 


\section{Chapter 4: Selling Yourself Online}

The concept of identity is rather large. Everyday humans do certain actions and behaviors which are supposedly in congruence with our identity, or identities. Turning our attention back to the shoe analogy, I argue that men who would don a pair of Ariats would try to embody a rugged masculinity. I am viewing the shoes as a symbol of the cowboy, one who is associated with ruggedness, so I believe it is here that I should discuss the symbolic interactionist Goffman and his theory on self-presentation. He theorized that individuals present themselves to others through impression management; an individual's sense of self is developed from the creation of an impression they wish others to observe (Goffman 1959).

If I were to wear cowboy boots out to a bar, I am attempting to create an identity for myself by managing the way other individuals would perceive my attire (the wearing of items stereotypical of a cowboy would lend credit to myself embodying a masculine identity). The importance of the theory is how the sense of self is created from impression, since I am arguing that the MSM (men who have sex with men) who use the Internet for hooking up are proffering information about them to create an "ideal persona." This persona may or may not reflect the actual identity of the person; for this study it is impossible to assert whether the two identities are in congruence since I only have the data presented in the profile. While a follow-up study to determine if this disparity does exists is a possibility for future research, for this project I am focusing on how the men present themselves in the ads at that snapshot in time.

The review of literature up to this point has focused on the masculinity and sexuality of the men this project seeks to study, but we have not discussed yet the realm in which these depictions of masculinity and sexuality take place, namely the online community. Hatala, Milewski, and Baack (1999) offer several reasons that online personal ads are much more 
practical than print media: the Internet allows people to meet other people from around the world, the personals site is capable of conducting searches related to specific desired criteria, the communication provided by the Internet is cheap and fast, and the Internet provides a high level of anonymity. Computer mediated communications have affected the gay and lesbian community rather considerably by the computer's ability to offer a way for individuals to bridge communication gaps for people who may experience psychological or geographic isolation (Woodland 2000). In addition, Turkle (1995) believes that cyberspace exists as a safe haven for individuals to act on identities that may be oppressed in real life, or offline. I am convinced that this anonymity provided by cyberspace is sometimes important to the MSM since some of the men who engage in same-sex relations may be unable to show their alternative identity offline. I need to clarify the use of identity in the previous sentence; the word identity was chosen as a matter of convenience since many MSM do not identify as gay or bisexual, but see their sexual acts as separate from their actual identity.

While previous studies have shown that people in virtual communities exhibit similar behaviors of people in offline communities (minus the actual physical presence) (Rheingold 1993), more recent studies (Okie 2000) have shown that, especial for gay men, the online community is simply an initial start to an actual face-to-face meeting. In a survey of 856 individuals, Okie (2000) found that 88 people reported actually having intercourse with someone they had met online, and that of the demographic groups represented in the sample, gay men outnumbered the others in finding partners online. The study also discovered that those who sought sex online had a higher percentage of previous STDs than those who did not.

While there are problems in the content analysis of person ads, the ads are an excellent source of data for self-presentation since the advertisers are managing their impressions for 
potential partners, and not the researchers (Epel, Spanakos, Kasl-Godley and Brownell 1996). Another theory that I will briefly discuss here is the idea of the general exchange theory which argues that individuals are goal-oriented and will attempt to gain something through an association by offering something in return (Gudelunas 2005). I believe that the main purpose of logging on to a sex-seeking site is obtaining a desirable partner for a sexual relationship or encounter. When the MSM logs onto the site and creates the profile, he is searching for sex, and in accordance with the exchange theory, will attempt to procure this hook up by offering something, namely he, in return. I argue, however, that sex may not be the only thing the MSM offers in return for sex, but such gifts could be money or even simple companionship.

While studies in the 1970's (see Lee 1976; Lumby 1977) focused on the descriptive categories seen in gay male ads, Reige-Laner and Kammel (1977) preformed a study to compare gay and straight male personal ads. The two discovered that socially desirable characteristics were maximized in the ads while negative traits were minimized for both but gay males were more specific in their relationship goals and gay men portrayed more stereotypically masculine qualities. Phua et al. (2009) conducted a study on male sex worker's online ads and found that almost 37 percent of the 203 ads identified the person as jocks, real men and/or similar hypermasculine qualities. They also discovered that those who mentioned their genitalia were less likely to mention health (coded as the mentioning of 'disease' or 'HIV') and that a relationship existed between those who mentioned their genitals and self-identified as tops (those who do the inserting during anal intercourse). Phua et al. (2009) reasoned that those who identified as tops did not mention health in their profiles possibly because of the perception that tops are at less risk of contracting HIV than bottoms (those who receive during anal intercourse). Smith (2000) found a significant association with indicators of safety and indicators of discretion. 
An important study conducted by Gudelunas (2005) which analyzed over 200 gay personal ads included a component for analysis that my study also seeks to investigate: the difference of information on the profiles relating to the individuals location in a larger city versus a smaller city. Men and women who identified as gay/lesbian were more likely to be from a larger city and those who were from a smaller city were more likely to classify themselves as bisexual, questioning, or straight. The differences here I believe are a direct result of the location of the individuals because small towns tend to be more close-knit and socially conservative, thus prompting the individual to attempt to hold on to the ideal of being straight. Along with this, he also found that masculinity was of concern for men in small towns that sought partners who were straight acting. Small town individuals were also less likely to post a picture to their profile, which also lends credit to the argument of wanting to retain a level of anonymity in the small town. However, Gudelunas (2005) did point out that since gay men tend to be focused on the physical aspect of the individual, a lack of a photo did not dismiss the preoccupation with aesthetic qualities; many ads (mostly from small town males) spend a great deal of space describing their build and other physical qualities.

The final point I would like to mention from Gudelunas' study is that advertisers were interested in moving from online to offline communication, not overly concerned with retaining anonymity, and were not interested in the idea of playing around with multiple identities. While studies have shown that the online realm exists as a way for individuals to experience different identities and genders (Manago, Graham, Greenfield, and Salimkhan 2008), the individuals in Gudelunas' study did not display this phenomenon. I believe that my research will yield the same findings with regards to identity creation. As we have seen with the exchange theory, individuals will attempt to reach a goal by offering something in return. If person A logs online with the goal 
of getting laid, he may offer a something specific (perhaps a masculine persona) to entice person B to engage in a hook up. If person A claims to be an aggressive top, he is offering this to a potential mate who may want to be dominated during the intercourse; therefore, person $\mathrm{A}$ is achieving his goal of getting laid while offering his dominating qualities to person B.

To reiterate the objectives of this study, the first is to see how men on ManHunt.net, a popular gay cruising website, are presenting themselves in accordance with what is ascribed by hegemonic masculinity. I plan to discover what traits are important to these men, and if these traits coincide with what the literature says about masculinity, or if the traits embody something else. The data will be explored both qualitatively as well as quantitatively. Focusing on the idea of actual executions of behaviors of masculinity, I believe that the men in the online community are capable of executing both feminine and masculine traits simultaneously. The second and third objectives seek to determine how age and rural or urban locations of the individual affects the prevalence of the aforementioned traits. 


\section{Chapter 5: Methods}

The primary tool for analysis in this research project is content analysis. This type of analysis is a systematic and objective way to quantitatively and qualitatively analyze the characteristics of a message (Neuendorf 2003). Essentially, content analysis seeks to count the number of specific items or reference in a given body of text and then catalog the counts into a classification from which interpretations can be made (Thayer, Evans, McBride, Queen and Spyridakis 2007). There are two ways in which content analysis can be utilized. Neuendorf (2003) argues that for academic content analysis, the variables should connect with one another to form hypotheses or research questions. A second way is an exploratory content analysis where no hypothesis exists prior to initial analysis and through emergent coding, the researcher sense common themes and devises an empirical way to study those themes (Thayer et al. 2007). For this study, I employed the exploratory content analysis for data analysis. While I had reviewed what the literature said on masculinity and sexuality, I did not have any specific hypotheses prior to data analysis. I simply used the literature review to guide my research.

The content analysis occurs at two levels depending on the type of content being analyzed (Thayer et al. 2007). One of the levels in known as manifest analysis, or the simple counting of words or phrases found in the text. This level does not require interpretation from the coder, but a simple tally of surface features, such as pronouns or names of occupations. This is also the first step in grounded theory (Glaser and Strauss 1969) known as open coding where the names and events in text are constantly compared with each other. Thayer et al. (2007) also described the latent level of analysis where the researcher interprets the underlying meaning of the text. This is often the more difficult of the two since the researcher must clearly define what 
is being measured. This method is often used when the results may not be able to be repeated or when the research wants to test their hypotheses on a small sample group.

Two measurement methods exist for examining social phenomena: deductive and inductive measurement (Thayer et al. 2007). Deductive, or top-down, measurement needs the researcher to have developed specific coding strategies before conducting a content analysis where inductive, or bottom-up, measurement allows the basic research questions to emerge from the analysis process. For this study, I employed an inductive approach. This is also the second part of grounded theory known as axial coding (Glaser and Strauss 1969) where the researcher begins to cluster the open codes into groups with common, or "axial themes." The third part of grounded theory, known as the selective or "thematic" coding, is where the researcher begins to examine the underlying themes from the interrelatedness of the axial codes (Harry, Struges and Kilngner 2005). The final part of grounded theory would be the development of the theory itself. Once I had analyzed the data, I developed a theory of the how the men in the study were negotiating their sexual behaviors with what was ascribed by the dominant masculinity.

\section{Sampling}

The data were collected between October 2009 and January 2010 using the website ManHunt.net, which is a large MSM-focused website accessible over the Internet. This website was chosen because it is free to anyone (although by paying a small membership fee allots more options to the member), has a large clientele of approximately 2 million subscribers worldwide, and allows members to search for others based on various components including location, age, and sexual practices. Members are able to upload photographs and describe themselves in as much detail as desired in the main text of the profile. Members are also able to indicate the specific types of relationships they are seeking (one-on-one sexual encounters, group sex, 
friends, long-term relationships, etc), as well as specific desired sexual acts (kissing, leather, married men, oral sex, etc).

The log in page for ManHunt.net is arguably designed to attract customers and does so in several ways. The first thing one might notice is the image of barely clothed man plastered on the right side of the screen. Each time an individual visits the log in page, a new image of a different male is presented, sometimes the male is clothed in jeans and a t-shirt standing and smiling, while other times he is wearing nothing but a jock strap and poised to launch a football towards some unseen target. Although the website does not claim that these men are actual members of the site, by placing various sexually attractive men on the log in page will either give the individual that impression, or at the very least peak his sexual interest in order to draw him into logging on. The log in page also displays the current number of men currently online, at times boasting numbers upwards of 40,000. A number like this may seem large until one realizes it is the global number of men currently logged on; yet it shows to the potential buyer (while the website is free, the free members have limited access to profiles and limited e-mail capabilities) that the website is very actively used. Three words in appear in bold just above the log in prompt, "Cruise. Chat. Connect." These words give the reader the impression that using this website is rather straight forward in that he will be able to cruise (look around at the profiles), chat with individuals that he finds appealing, and then finally connect (meet up for an interaction, sexual or otherwise). By using the word "connect" the website appeals to a wider variety of men; someone who is truly looking for friendship on the site can interpret the word "connect" as meeting for coffee while someone looking strictly for sex will see "connect" as synonymous with hooking up. The definition for "hooking up" can vary from person to person, but for the purpose of this study, hooking up was defined as any interaction among the men that resulted in sexual 
gratification. Finally, the log in page informs the reader that "If he's out there, he's on here" in an attempt to entice the potential buyer to use their services.

Once the individual has entered the site, he is able to search for men via certain criteria (such as age, location, sexual interests, body type, etc.). The profiles are designed with the profile picture on the left side of screen just below the individual's user name. The right side of the profile is essentially standard in each profile and is where the individual indicates their basic information (age, sexual position, height, weight, ethnicity, penis size, HIV status, hair color, eye color, and body type) as well as their sexual interests. For this section of the profile, there are predetermined answers for the basic information, and the individual selects from the lists what information to include in their profile. Some profiles contained information for all areas, while some profiles only indicated their age. The center of the profile provided the individual an area to freely type information about themselves. Some individuals chose to include lengthy descriptions about themselves or interests in the free text area while others chose to leave this area blank.

A total of 480 ads were collected from 16 states across the United States from the samesex oriented hook up site ManHunt.net. The U.S. Census divides the country into four regions: Northeast, Midwest, South, and West. Four states from each region were chosen at random, and each state was broken down into rural cities and urban cities. Census data (2000) was used to determine which cities were in a rural classification and which cities were urban. The Census uses nine definitions to denote a rural setting and two of these definitions were used for this project: all counties outside metropolitan areas in 2003 (based on 2000 Census data) and all census tracts with 2000 Rural-Urban Commuting Area Codes 4 through 10. These two 
definitions best encompassed the differences between rural and urban in respect to the ease of connecting to the social and economic characteristics of urban settings.

The two definitions were entered into a mapping utility provided by the Census and a color coded map of each state was generated, one color denoting the areas that fell inside of metropolitan areas and another color denoting the census tracts with RUCA codes 1-3. Areas that fell outside these two definitions were considered rural and appeared as white on the map. From the color coded map I was able to choose three rural cities, three urban cities and collect 5 ads from each state (a total of 240 rural ads and 240 urban ads were collected). The profiles were selected as Manhunt.net generates a list of profiles for each city or location. It is important to note here that the list of profiles is generated with the most active user's profile appearing at the beginning of the list; the first five from each list were chosen for analysis. The most active profiles are from the men who are most actively involved in the site, and therefore most active in the creation of their masculinity.

\section{Operationalizing the Variables}

Demographics. The profiles were coded for the following demographics: whether the profile was from a rural or urban location (determined by Census data), regional location (Northeast, Midwest, South, and West), age of individual, individual's race/ethnicity and individual's HIV status (positive, negative, no answer, ask me, don't know).

Photographs. Photograph data was obtained; the ads were visually inspected and profiles were either coded as missing, face picture, body picture (focusing only on the body and not the genitals), exhibition (focusing only on the genitals or anus) or multiple (showing a combination of the body, face, and/or exhibition). The term "sexualized" was created to better describe and differentiate the photos. Unfortunately, the actual photographs are prohibited from being 
included in the paper due to privacy issues, but a description of two photos illustrates the difference. Imagine two photographs, both of men sitting in a chair. The first photo depicted the man sitting straight up in the chair, both hands placed just above his belt. His head is cocked slightly to left as his vision is fixated upon something out of the camera's view; a bright and personal smile on his face seems to have been caught at the moment of peak amusement. This photo was coded as "not sexual" since his admirable, but rigid posture and averted gaze from the camera hardly classifies as enticing. The second photo depicted the man sitting slouched in the chair, his left arm resting haphazardly on the back on the chair while his right hand forms a tight fist around the bulge in the front of his unbuttoned jeans. He is starring directly at the camera, as if into the eyes of the person viewing the profile, and his mouth is slight open as he if is expelling air due to the euphoria that he seems to be experiencing. The provocative pose, alluring gaze, and shirtless torso landed this photo, and many others like it, in the sexualized category.

Identifying Masculinity Indicators. I began the process of open coding with the first 100 profiles in my analysis. After the initial analysis I employed axial coding to develop the indicators of masculinity. For example, in the process of finding the various sexual interests indicated by each individual, I began to notice that a certain number of the sexual interests were considered "high risk" based on criteria from the Centers for Disease Control and Prevention (2010). Thus, the indicator of "risky sex" was created. The indicators are as follows: identifying as straight or "straight acting"; interest in risky sex (practices with increased the chances of contracting STD/HIV such as swallowing ejaculatory fluid, mentioning of "rough sex" or "pig play" since both are associated with physical aggression and engaging in unprotected sex, "fisting" since this could result in the tearing of anus which leads to a higher chance of contracting STD/HIV, "S\&M" since the possibility of physical damage is present, and "group 
sex" since engaging in intercourse with several partners is associated with increased likelihood of contracting STD/HIV); submissive qualities (being used sexually); bodily strength (gym bodies, muscles, physically fit); regular (an average Joe, laid back, "one of the guys"); bear persona (being hairy, rugged, chubby); penis size (indicating the size of their penis); discreet (being discreet about the sexual encounter); jock (athletics, playing sports); seeking safe sex; seeking no strings attached sex; seeking a partner free of sexually transmitted diseases; seeking friendship; seeking dating/commitment. If the profile mentioned one of the above at least one time, it was coded as "present" in the profile. The profiles were also coded for the presence of traits that were portrayed by the individual as well as the traits that were sought in a potential partner. The indicators mentioned above were not mutually exclusive; often they tended to appear alongside other indicators in several profiles.

Quantitative analysis, more specifically crosstabs, was also employed to investigate if any statistical differences existed between the profiles based on the individual's location in a rural or urban setting. Crosstabs were also used to investigate any differences that the age of individual had on the profiles. The age of the individual was transformed from a scale variable to a categorical one for ease of analysis. The variable of age was grouped into the following categories: 18-29 (young), 30-45 (middle), 46 and above (older). While Barker (2004) and Hostetler (2004) found that gay youth discourse deemed the age range of 30 to 45 as older, I added a middle aged category to better explore the differences seen with age.

The literature review has by now laid the groundwork for the bridge that connects masculinity to the self-presentation found in the online advertisements. Masculinity is held in high regard, both by heterosexual and homosexual men. The men in study have taken aspects 
from masculinity and applied them to their presentation in the ads. So while I argue that certain aspects of masculinity are of importance to the men, I must stress that this small subset of the gay population cannot speak for the entire community. Not every gay male utilizes the Internet for the purpose of networking or hooking up. Some may utilize existing social networks that are developed through mutual friends or coworkers, while others may prefer gay clubs or bathhouses.

Another important factor to consider is the method of data collection. While measures were taken to collect ads from rural and urban cities throughout the United States, the manner in which they were collected yielded the ads that were most often accessed. I argue that this selection method is completely reasonable because the men who access the website most often are most often engaged in the presentation of their self. Someone who has not accessed their profile in over a year is not indicative of the other men who frequent the website of regular basis. The presentation seen in the ads are representative of people seeking hookups on ManHunt.net. Men using other websites hook up sites may present themselves differently than those seen here. ManHunt.net is designed to be used by a general audience; indeed, a website that is geared to sadomasochism will arguably stress more elements of submission and control.

The first objective for my study was to explore gay men were creating their masculinity, based on the ascribed traits of the hegemonic masculinity, in their online profiles. Both the literature review of masculinity and sexuality and the initial analysis of the profiles contributed to the naming of the indicators of masculinity that I coded for (risk, penis size, being outdoorsy, etc.) Once these indicators had been totaled, I peered into the data trying to determine what the relationships between the various codes were trying to tell me. Using the literature and the data as a guide I developed the four aspects of masculinity I found to be important to the research: 
risk, vitality, strength and emotional detachment. Not only was the data indicating that these four traits existed, but previous research on masculinity has shown these to be essential aspects to those trying to embody hegemonic masculinity. In addition to the four traits the embodied masculinity, I had discovered that there were four other traits that appeared to be in stark contrast to what the literature had indicated about masculinity: seeking straight men (as opposed to being straight), being sexually submissive (as opposed to be sexually dominant), seeking safe sex (as opposed to disregarding safety and embracing risk), and seeking friendship/commitment (as opposed to disregarding emotional attachment).

The second and third objective sought to determine how the prevalence of these traits differed across age groups and across rural and urban locations. The literature has shown that a preoccupation with youth exists in the gay community (Barker 2004; Goltz 2007). Due to this I had reasoned that men of different ages may place more emphasis on different aspects of their profile. Research has also documented the effect of rural and urban locations on the gay community (Preston et al. 2004), where rural areas tend to be more conservative than urban areas, and as a result may affect the way gay men present themselves. 


\section{Chapter 6: Findings}

For this study, I focused on user demographics, such as ethnicity/race and rage, to show the type of website user; I used a qualitative research method to explain the use of masculinity traits, i.e. whether the user embodied, would negotiate, or completely reject masculinity; and I used a quantitative research method to examine the effects that age and location have on the prevalence of the traits within the profiles.

\section{Sample Characteristics}

The sample consisted of 480 profiles from the website ManHunt.net. Of the total profiles, 240 were collected from rural locations and 240 were collected from urban locations; with 120 profiles selected from each of the four regions of the country (Northeast, Midwest, South and West). The mean age of the 473 individuals who indicated their age was 35.30 years, with a median of 35 years, a modal age of 25 years, and a range of 18 to 79 years of age. The ethnicity breakdown of the 345 profiles that indicated their ethnicity is as follows: Asian (2.0\%), Black (2.3\%), Latino (2.9\%), Middle Eastern (0.6\%), Mixed (4.6\%), Other (1.2\%), and White (86.4\%). 329 profiles indicated the individuals HIV status with $0.6 \%$ saying they did not know their current status, $2.1 \%$ saying there were HIV positive and $97.3 \%$ saying there were HIV negative.

As we begin to discuss the findings of the study, I must reiterate that the profiles are evidence of how the men present themselves, and may not reflect their actual demographics or behaviors. As with all social sciences, the problem of self-reporting and being seen by others in a positive light is always a concern for researchers. While creating an online profile is not the same as filling out a survey, the individuals will arguably still volunteer certain information that will maximize their potential of being seen as appealing by others. Lee (1976) and Lumby (1977) found in a study of gay and straight male personal ads that desirable characteristics were 
maximized while negative characteristics were minimized. My study does not claim to describe the men using ManHunt.net, but rather seeks to explore what the gay men in the study are presenting in profiles in order to locate a hook up. This is important because as described by the exchange theory, individuals will attempt to gain something by offering something in return (Gudelunas 2005). Since the general purpose of individuals on this site is to gain some sort of physical connection, I argue that men presenting themselves as masculine is something they can offer to others since masculinity is held in high regards for many gay men. As mentioned before, the definition of a hook up for this study is any real time (offline) physical interaction that results in sexual gratification for the men involved.

Four hundred and twenty profiles contained a photograph and while only $23.3 \%$ of the photographs were of the individuals face, $41.9 \%$ were nude photographs and $52.1 \%$ were considered to be sexualized. Of the photos contained in the profile, it is important to note that just a little over a fifth of them were of the individual's face. This may be due to individual's wanting to conceal their identity as research has shown that one of the main benefits offered by the Internet is the level of anonymity (Hatala, Milewski and Baack 1999). However, it seems unlikely that a married man would need to hide his face picture in case his wife was to join the website. While ManHunt.net is opened to anyone (over the age of 18), it is geared towards individuals who are online with the specific purpose of looking for a same sex hook up. It seems very unlikely that the general public would be exposed to the website. The individual would probably have a better chance of being discovered at a gay bar than on a sex-seeking website.

A large number of men indicted "white" as their ethnicity. One may argue the socioeconomic inequalities may result in this disproportion; however, this claim or any other reason for this imbalance cannot be investigated at this time. Of the people who indicated their HIV 
status, nearly $98 \%$ claimed to be HIV negative. Here is another instance where we must reflect upon the nature of self-presentation and portraying desirable characteristics in the profiles. It is entirely possible that nearly all the men in the study are actually HIV negative, but one must look at the result and question its validity since sexual promiscuity is correlated with an increased chance of contracting an STD.

\section{Portraying and Seeking in the Profiles}

As the analysis began on the profiles, it became apparent that the men were not just presenting information about them, but also indicating certain traits that they preferred in their potential partner. The traits that were portrayed and sought were those I believed to be indicators of masculinity since I argue that men on ManHunt.net were focusing on aspects of masculinity in order to attract a potential hookup. Table 1 (Appendix A) displays the percentages of traits that are sought after as well as portrayed by the individuals. Sexual risk did not have a percentage for "sought" because it was understood that by portraying a specific sexual interest (such as role playing) that person also sought to engage in this sexual practice with a potential hook up. Other traits did not have percentages for "portrayed" because they were traits that were specifically sought after (such as an STD free partner or friends).

\section{Identifying the Traits of Masculinity}

It is now important to discuss how the categories, or "traits", of masculinity were created. After the initial analysis of the first 100 profiles, I had a list of the indicators that were appearing throughout the profiles. From these indicators, I developed further axial and thematic coding to arrive at eight "traits" that were emerging from the profiles: risk, virility, strength, emotional detachment, seeking straight/bisexual partners, safe sex, being submissive, and seeking friendship/dating (see Appendix A). Both coding and reference to previous literature were used 
in the development of the traits. For example, the strength trait was comprised of the following indicators: body boasting (possessing a muscled or "gym" body), being outdoorsy, being an average Joe, having a bear persona, and being a jock. If a profile was coded for being present with one of the previous indicators, then that profile was coded as also possessing the trait of strength. Essentially the strength trait, as well as the others, was created by collapsing several indicators into one trait. The traits were then compared to what the literature deemed to be essential to masculinity to see if they were embodying or rejecting masculinity. We will first discuss the four traits of masculinity, and then turn to the four traits that represented the negotiation of masculinity seen in the profiles.

\section{The Four Main Aspects (Traits) of Masculinity}

It is from the words of the men themselves that we are able to uncover more information about their views of masculinity. The first part of this analysis focuses on the four main aspects of masculinity seen in the profiles: risk, virility, strength, and emotional detachment. I have argued that men in this study will be emulating masculinity in their profiles since numerous studies on gay men have indicated that there exists a preoccupation with the aspects of masculinity for some gay men. Therefore, the four traits of masculinity described below were not only created from the data but guided by what the literature has shown. For example, Courtenay (2001) and Bunton and Crawshaw (2002) have argued that what is considered to be masculine in the United States may produce self-destructive and risk taking behavior, ergo, the men in this study will be portraying elements of risk in their profile since they are preoccupied with being seen as masculine in their profiles. The other three traits to masculinity were developed in the same way, both directed by what the literature had found and what emerged from the data. 
Risk. The concept of risk is seen throughout the literature in masculinity; in order to achieve masculinity, one must partake in risky ventures (Hamilton and Mahalik 2009). The men in this study are portraying an engagement with a specific type of risk: sexual risk.

Approximately $36.3 \%$ of the profiles were coded for the presence of risky sexual practices (those practices that are correlated with an increased chance of contracting an STD). As we begin the examination of the profile text it is important to keep in mind the profiles are not mutually exclusive meaning that usually one profile will not focus on only one aspect of masculinity. The excerpt below is evidence of the risk aspect as well as a submissive aspect.

"Love to suck cock, eat ass, get fucked, cum swapping/eating, feet fetish, role play, w/s, and more."

This excerpt mentions the practice of cum swapping and eating, which is exactly what it sounds like: the transfer of an individual's semen to the other male with the intention of swallowing. The risk aspect is apparent since the transfer of bodily fluid such as seminal fluid is vehicle for viral and bacterial infection, yet this practice also speaks to a bonding between then men. While anonymous sex with many partners has inherent risk associated with it, the male here is describing an active role. He is focusing on the intentional transfer of bodily fluid to the other person, not necessarily to infect the person, but to engage in a risky practice that may not have occurred without an expressed desire. Not only is he engaging in risky practices by accepting the other male's semen, but he is helping his partner to obtain the risky aspect by ingesting his semen; this may act as a bond between the two men, both physically (the semen) and symbolically (that both men are partaking in the same risky endeavor). The second profile below mentions the risky practice of barebacking or UAI (unprotected anal intercourse) used...Suck, swallow, rim, WS, bb, groups, etc...Pissers even make me nastier." 
As mentioned before, $\mathrm{UAI}$ is an extremely risky sexual practice due to the possibly of a fissure in the anal tissue resulting in an entry point for viruses and bacteria. Halkitis and Parsons (2003) provide a conservative estimate that $14 \%$ of gay men engage in UAI. It is important to note that UAI in this sense is not a result of forgetting to use a condom, but the intentional disregard for condom use during sex. Wegesin and Meyer-Bahlburg (2000) found that HIV negative men who engage in UAI employ strategic behaviors to minimize the risk of infection such as being a "top", or insert during coitus instead of being receptive. When the man is the top, he is considered at a lower risk for infection because the skin on his penis is less likely to tear or rupture than would be the anal tissue of the bottom, or receptive partner. So while barebacking is not void of all risk, it appears that men are still engaging in some form of risk management to lower their chance of contracting an STD while still participating in a risky sexual practices that allows them to obtain a level of masculinity. More on risk management will be discussed when we review the negotiation of masculinity in the profiles that seek "safe sex." The individual also indicates his desire for swallowing (the semen of) men and for "groups" or engaging in sex with more than one partner at the same time.

Stemming from the practice of barebacking is the phenomenon known as "bug chasing" or the active seeking of seroconversion by engaging in unprotected sex with HIV positive partners (Maskowitz and Roloff 2007). Bug chasers may also be HIV positive men searching for reinfection or take on the role of the "gift giver" or someone who acts to purposely infect a bug chaser. I must stress that bug chasers are a subgroup of subgroup and in no way do I intend to say that all gay men partake in this practice, but a discussion of bug chasers is necessary to demonstrate the element of risk being undertaken by some of the men in the study. An excerpt from a profile (below) depicts the act of UAI with an HIV positive person.

"40s gwm couple looking for NS fun. Redhead with tats is (+) will bb ONLY..." 
The sentence above, translated from an online vernacular, says that a 40 year old gay white male couple is looking for no strings (referring to no attachment, as in perform sexually and then hit the road) fun. The "redhead" refers to the tattooed gentleman in the picture, who is HIV positive (indicated by the "+") and will bb (bareback, or engage in anal sex without a condom) only. Not only does the individual indicate that he will have sex without a condom despite his positive status, but that barebacking is the only way he will agree to have sex.

What is interesting is the purposeful seeking of risk that will almost certainly end with a negative health consequence. Society has depicted men engaging in forms of risk to validate their masculinity, one example being drag racing. It is entirely possible that the men engaging in the drag race do not want to wreck their car or injure themselves, but rather desire to skirt around the danger. What we are seeing in these profiles is a desire for the danger (HIV infection), not just the risk of HIV infection. The profiles not only demonstrate a desire for the danger, but inform the potential sexual partner that they must also be willing to engage in similar sexual practices. The profile below describes himself as a positive man who will only engage in UAI and will not "pullout"- remove his penis from the partner before ejaculation.

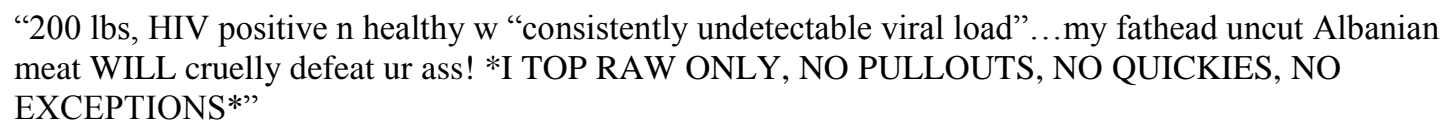

This profile also mentions he has an undetectable viral load, meaning that his blood shows no evidence for the virus. This does not mean he is cured, just that at the time of the test, they were unable to find copies of the virus in his blood.

The second profile (below) demonstrates the emergence of a culture or brotherhood for men who are positive and seeking other positive men.

"Looking for my RAW POZ HUNG men..POZ BAREBACK ONLY, NO BI OR NEG...If you DON'T have love for your POZ brothers, then you ain't got love for me" 
This profile mentions a "love for POZ brothers." Fraternities often provide an avenue for a male bonding experience; perhaps this subgroup of men see their desire for risk and danger as a way to develop that brotherhood seen in other aspects of masculine male culture.

We must ask why these men are taking the aspect of risk from masculinity as essentially shattering through the risk in pursuit of actual danger. AIDS fatigue is a phenomenon that occurs in some men who feel that they can alleviate their constant worry of contracting HIV by intentionally infecting themselves. This may be one of the reasons why men have engaged in such practices. However, for this study, I believe that not only do these examples show how the men are employing risk in their affirmation of masculinity, but this "risk culture" also acts as a way for camaraderie or brotherhood.

Virility. The second aspect of masculinity demonstrated in the profiles is virility, or more specifically the size of the man's penis. Society places an emphasis on the ability of the man to perform in the bedroom, as seen with the large distribution of and advertising campaigns for various erectile dysfunction drugs as well as male enhancement drugs. In a study by Nugteren, Balkema, Pascal, Schultz, Nijman and van Driel (2010), it was found that the erect penis has been a symbol of masculine quality and because of this a smaller penis may cause insecurity or embarrassment. While the concept of penis size was not initially reviewed in the literature, as with true grounded theory, the aspect of penis size did arise in the data. While only $1.9 \%$ of the profiles mentioned searching for a specific penis size, more than one-fifth $(26.3 \%)$ of the profiles indicated the male's penis size. Some of the men gave specific measurements, such as length and width and whether they were circumcised or not, while other men used descriptive words in the text to elaborate on the size of their penis. In a profile mentioned above in the risk section, we saw that one man described his penis as a "fathead uncut Albania meat." Using the word "fat" in 
the narrative attempts to convey the image of a thick penis, as with his other euphemism for his penis (meat). The two excerpts below also use various words to elaborate on the size of their penis.

“30's gwm with huge tool to use for mine and your pleasure"

“...thick, hung, and well-endowed jock type...”

These terms (thick, huge, uncut, cut, well endowed, long) show the importance that the men in this study place on the size of their penis. It is important again to note that the majority of the men portrayed their penis size than searched for a specific size (see Appendix A). This suggests that the men are more concerned with possessing a large penis as their own than simply having a partner who is well endowed. While some aspects are sought after, such as risk, this aspect seems to be one that men feel they must possess on their own. A possible reason for this is studies have shown (for example, Bird 1996) a level of competition exists between men and perhaps this is just another way that the men in the study can compete with each other. If the man meets a potential hook up, he may become uncomfortable if his penis is smaller than his partner's; this of course is all speculation.

Strength. Society has consistently portrayed the masculine men as those who possess a considerable amount of physical strength. Several traits that began to emerge in the analysis were a muscled body, outdoorsy or "frontier masculinity", being an average Joe, a bear persona, and being athletic or a jock. The underlying idea among these five traits was the element of strength; it was this reason that persuaded me to collapse all five of these traits into the aspect of masculinity labeled "strength." Approximately $37.5 \%$ of the profiles contain the strength trait. Of these 180 profiles, $19.2 \%$ portrayed themselves as having muscles or a gym body, $5.6 \%$ portrayed themselves as outdoorsmen or enjoying nature, $9.4 \%$ classified themselves as a regular Joe or average guy, $10.8 \%$ classified themselves as possessing the bear persona, and $2.1 \%$ 
claimed to be a jock. The profile below indicates that the individual only wants to converse with men who agree with his fit and healthy lifestyle.

"Hot, educated guy looking for other hot guys to hang out with. I think looking good, working out, and being healthy are important and only want to hear from guys who agree."

Research has shown (Kendall 2004; Rofes 1997) that gay men tend to place a large emphasis on the aesthetic nature of the male body. Notice how while the men talk of working out, they do not mention their bench press weight or how physically strong they actually are. I believe that the appearance or aesthetic nature of strength is more important that actual strength. These men describe working out and staying fit, yet they appear to believe that the mere mentioning of working out is enough to employ the image of a strong physique. This may be an example of the complicity with masculinity; often men are unable to actually achieve a certain level of masculinity so they will attempt to reconcile this stress by achieving an association with the masculinity. Not everyone is able to be a power lifter, yet by appearing to possess muscles may give the allure of strength. Below is a narrative from a profile that focuses on the working class eroticism of the working class body.

\footnotetext{
"Husky, Stocky... one who likes working on old cars, home improvement. men that is a somewhat of a mechanic, farmer, guys of blue collar workers, guys like working with their hands. Motor cycle riders, atv's bikers, leather wearing boots, hiking, bike riding the bike trails. camping in the woods, sleeping under the stars..."
}

We see in the above profile how the men in the study are focusing on the aesthetic nature of masculinity, most notably found in the bear subculture. Hennen (2005) described the bear culture as one that is focused on authentic masculinity, such as jeans, bears, T-shirts and striving to be just one of the guys. In the narrative we can see that the man focus on the qualities that an "authentic" man should possess: "working on old cars", "home improvement", "blue collar workers". The narrative below mentions that you can find this particular man at a sports bar during a UFC fight; clearly a portrayal of being "just one of the guys" watching a fight. 


\begin{abstract}
"Masculine guy like doing sports, working out, outdoors tinkering on house. Workout at S Charleston Community center and can be found at Quaker Steak n Lube during UFC fights. looking for a muscle type fantasy with lots of flexing and muscle worship. Two major turn-ons: Biceps and wrestling/rough housing."
\end{abstract}

While mentioning a desire for farmers and car mechanics may not be considered sexual practices, the image of authentic masculinity that is associated with these types of men encourage sexual arousal. One of the individuals focuses on the sexual appeal of nature (camping in the woods and sleeping under the stars). Popular culture has often associated masculine men with being "outdoorsy" or possessing "frontier masculinity."

The elements of strength here appear to be more of a practical strength. For example, the earlier profiles focused on the muscled body, where the two profiles above mention the ability to work on cars or "tinkering around the house." These demonstrations of strength focus on abilities that traditional masculinity requires of men. The inherent vanity associated with weight lifting seems to be overlooked with the profiles that focus on the authentic nature of masculinity. While they do not claim to be able to lift 300 pounds, working with their hands and fixing cars allows the male to describe a different facet of strength.

Another facet of strength that we can see develop in the profiles is the idea of a "manly" strength, or how strong the male is in the expected social behaviors of men. As shown in the profile of the man who mentioned the UFC fights, we see that one individual talks about watching fights at a local bar and being "just one of the guys." He believes that authentic men enjoy the aggression and displays of physical strength from UFC fights and that the appropriate way to enjoy this sport is in the company of other like-minded men. The idea of frontier masculinity encompasses the idea that men should be able to survive and prosper on the frontier, or at the very least in an outdoor setting. One individual is stressing his "manly" strength by focusing on various outdoors physical activities. We can see how the men are portraying 
themselves in a way that matches what society has come to expect of traditional masculine men. They are attempting to portray themselves as strong men, in the aesthetic, physical, and practical nature, as well as the overall strong tie to masculinity itself. A weak male may not be physically weak, but weak in the sense that they do not embody the traditional values of masculinity.

Emotional Detachment. According to Brannon's Sturdy Oak cluster of the traditional male norm, emotional detachment is necessary for men to be confident and independent (Brannon and Juni 1984). While Keen (1991) argues that masculinity must be fostered by a withdrawal psychologically from women, the men in this study are seeing emotional detachment as keeping their sexual interactions void of emotional detachment. Approximately $60.4 \%$ of the men in this study indicated they were seeking NSA (no strings attached) sex. An element that was associated with the NSA sex was being discreet about the sexual encounter $(7.5 \%$ of profiles portrayed themselves as discreet while $5.0 \%$ of profiles sought someone who was discreet). The element of discretion appears to be a two-way street, meaning that while the person identifies as discreet, they expect their sexual partner to be so as well. The linkage between NSA and discreet for the profiles below seems to be related to the fact the individuals desperately wish to remain secretive about their sexual encounters.

"28 year old lookin for no strings attached fun...I am bi/str8, not out to anyone, AND DON'T PLAN TO BE, so I am VERY discreet and very masculine..."

"Light complected black jock. Discreet, bi, pretty much straight into white jocks that are the same. No attitude, healthy, squeaky clean and tested."

In order for them to remain discreet, the NSA element is essential because if the sexual partner was to develop emotional ties to the closeted individual, it would risk exposing the sexual encounter. However, I argue that the main reason the men in this study are focusing on NSA is because of its inherent emotionally free nature. Often society has associated women with emotion during sexual intercourse while presupposing men to be void of such emotional 
attachment. The profile below depicts a sexual act with no emotional attachment and even portrays himself as not so much a person but rather a "pleasure-giver."

"INTO: J/O, X-TREAM ORAL SESSIONS, SLIDE \& GLIDE R/U/IN?? STROKE FUCKING, COME UP AND KICK BACK IN MY PLAY ROOM, PORNO, IT'S ALL GOOD, VERSATILE ORAL PIG MASCULINE...IF THE IDEA OF A MASC, MAN WITH A BIG DICK SERVICING YOU WHILE YOU KICK BACK, THEN YOU DO ME HARD TOO, SOUNDS COOL THEN HIT ME BACK..."

The above profile exhibits the NSA element of sex by describing the sexual encounter to consist of the man kicking back to porno while he is serviced. While the male does indicate he desires to be serviced too, there still exists a casual approach to the sexual encounter; the man does not indicate any desire for a movie or dinner prior to sex. The men in the study appear to believe that the sex they are currently seeking should be void of emotional attachment if they are to embody masculinity. A scene from the very popular movie Boondocks Saints (1999) depicts two men in bed presumably after intercourse. One of the men moves into cuddle and the other protests and calls him a "fag" for exhibiting such emotion after sex. I believe that the men in this study have come to associate emotional attachment during sex with femininity, and research has already shown that those interested in achieving masculinity have been taught to develop distaste for femininity.

The four traits or aspects mentioned above appear to be similar to those traits that are important to the dominant masculinity. This lends credit to the claim that gay men embody masculinity since they view the concept of masculinity very highly. However, only $7.7 \%$ of the profile contained all four traits of masculinity. This may seem that the men in the study do not care about masculinity as once thought. We will see in the next section that the men in the study may indeed still value masculinity but employ their own forms of negotiation to obtain masculinity while still exhibiting their desired sexuality. 


\section{Negotiations and Rejections of Masculinity}

Only $22.9 \%$ (110) of the 480 profiles contained no indication of sexual risk, virility, strength, and emotional detachment. It would appear that these profiles were not concerned with the presentation of masculinity and may have decided to reject it. While I cannot say that they are trying to reject masculinity by simply not including it in their profile, I can argue that they are not concerned with portraying themselves as masculine because studies have shown that when developing profiles, gay men will tend to maximize the positive traits about themselves. We will begin with the first trait of negotiation which I coined "straight seeking." I argue that this is a negotiation since dominant masculinity requires the individual to be heterosexual, yet the men in this study are not concerned with being straight but rather with hooking up with a straight/bisexual male.

Straight Seeking. The profile below is an example of the individual voicing a specific request for a straight or bisexual individual.

“...interested in straight, bi guys, married guys, don’t worry discretion with me..."

Not only is the individual interested in finding a straight male for a hook up, but also indicates a preference for married men as well. An interesting result emerged from the data with the regards to the number of profiles that mentioned being straight acting versus those who were seeking straight or at least straight acting men. While only $9.6 \%$ of men identified as being straight or bisexual, $24.4 \%$ of the men were seeking self identified straight or bisexual men. One of the aspects of hegemonic masculinity is heterosexuality (more specifically male heterosexuality) and the men in this study should have copied this aspect to be straight acting. We should expect to see the majority of the men in this study portraying them as straight acting if they are trying to achieve masculinity; however, the percentages appear to be in contrast. If we look at the social context of masculinity, we often see how individuals validate themselves 
through others. It appears that the men here are more concerned with being sexually involved with someone who is straight than they are concerned with actually being straight themselves. The men in this study negotiate this aspect of masculinity through the use of complicity; the men are able to achieve masculinity by being associated with the straight men.

Gay men who seek partners online tend to have an affinity for the straight acting or masculine, an example of which is the website StraightActing.com that was studied by Clarkson (2006). The author found that men in their study were engaged in a more detailed description of what is was to be considered straight acting while the men in my study were more concerned on finding a straight male than describing themselves as one. A common misconception that is heard too often is that same sex couples have to be the same as heterosexual couples in that there has to be a feminine partner and a masculine partner. This is simply not the case, and just because the men in my study appear to be more concerned with finding a straight acting partner, it does not indicate that they view themselves as feminine. Of the profiles that indicated either a desire for straight men or identified themselves as straight, nearly one-fifth (18.1\%) identified as straight and sought other straight or straight acting men. This supports the claim that not all same sex couples have such gendered partners as society sometimes believes.

Therefore, we can see that the men in this study have negotiated what traditional masculinity ascribes; the men do not have to be straight acting themselves but it appears that as long as they have a sexual encounter with someone who is straight acting, they consider themselves associated with masculinity. This paper has argued that some gay men possess an affinity for the masculine; while some aspects of masculinity are embodied (risk, emotional detachment) others may be specifically sought after (seeking straight acting men). 
Safe Sex. From the results discussed in the risk section of masculinity, it appears that the men in the study see sexual risk as large aspect of masculinity. Therefore, instances where men are taking steps to decrease sexual risk should be an indicator of a rejection to ascribed masculine traits. However, the men appear to use a risk management technique in order to both attempt to decrease the risk of contracting an STD and still engage in risky sexual practices that help to validate their masculinity. This "risk management" is the second way that the men in the study are negotiating what it is to be masculine.

Approximately $31.5 \%$ of profiles indicated they were seeking safe sex, while only $7.1 \%$ of men were seeking a partner free of STDs. One would expect these two traits to go hand in hand, yet I believe there is a specific reason for the disparity between the two percentages. The men are taking an active role in risk management by focusing on engaging in safe sex practices instead of relying on their partner claiming to be STD free. While an individual could indicate on his profile that his partner must be STD free, he is essentially placing his health in the trust of arguably a complete stranger he has met online for sex. Yet by controlling the situation and practicing safe sex, he takes back control of his health. The excerpt from the profile, seen below, is an example of the call for an STD free partner as well as the safe-sex stipulation.

"tested hiv neg, u b too, no bareback ever..."

While the profiles in this study did not contain information on the men's risk management practices, $42.3 \%$ of 175 men who indicated a desire for risky sexually practices also indicate they were seeking safe sex. This result supports the literature that found that men who placed themselves in risky sexual encounters were engaged in taking certain precautions to limit the possibly of contracting an STD. An example of risk management that may be employed by the man would be for him to consider if he had brushed his teeth or not before performing oral sex on his partner. If he had, he may consider abstaining from performing orally because 
brushing his teeth could have resulted in a tear or cut along the gums. Another example was men that engage in UAI will usually top (the one who inserts) because there is a lower level of risk with toping that with bottoming (Holmes, O'Byrne, Gastaldo and Lombardo 2008). So while the majority of the men in my study are seeking risky sexual practices, they are cognizant of the risks and are actively engaged in managing the risks. They are trying to get as close to the danger as possible without actually suffering damage.

Being Submissive. As with the discussion of supposed gendered roles in same sex couples, the question of how a man can embody masculinity if he is the one being penetrated during intercourse arises. Three-hundred and fifty-four men indicated their sexual position with $42.1 \%$ identifying as versatile (able to assume both roles during sex), $28.0 \%$ indentifying as a bottom, and $26.8 \%$ identifying as a top. The question arises that for the men who assume a receptive role some or all of the time, are they able negotiate their preferred sexual position with what is ascribed by masculinity? It appears this group of men is not rejecting masculinity itself, but rejecting masculinity's definition that to be submissive is to be feminine. Below are two profiles that portray the individuals as submissive yet still maintain a dominant role.

\footnotetext{
"I need hot guys 18-50 with 7 in or bigger to skull fuck me or pound my throat real good. Then I need you to grab my head/hair slam/ram your huge meat deep in my throat and yell 'CHOKE ON MY CUM FAGGOT' and force me to keep ur cock buried deep in my throat until u have drained ur nuts in my guts..."

"i need a guy who wants to take a guy who has never been with another guy before(me),and train him as his personal sex slave. looking for a guy for multiple encounters, who will only be interested in me for his sexual pleasure. $i$ only have a couple of restrictions, one of which is no kissing. Also, no extreme pain. if you write me, say more than hello, tell me how you would use me to please you, ill only respond to guys with a hint of imagination. ill be the slut you can get away to have all your nasty needs filled. no locals. no winks!"
}

The two profiles are taken from self-identified submissive men. An important distinction to make is that men who are bottoms are not always considered to be passive or feminine, as is the case with "power bottoms", or those who take the receptive role during intercourse yet still 
maintain aggressive control during sex. Being submissive or being used, as these men have described in their profile, may at first give the impression of being passive. However, the profiles are very explicit in the actions they want their partner to take. The first profile sets a penis size requirement ( 7 inches or bigger) and gives both physical and verbal commands that he expects his partner to take. The second profile also gives restrictions (no kissing, no local guys) and indicates he needs his partner to train him as a personal sex slave. These men are negotiating with the traditional belief from masculinity that to be submissive is to be passive; they are showing that as submissive men they are very active in controlling the hook up.

Seeking Friendship/Commitment. This aspect that emerged from the data appears to be the one in greatest contrast to the expectation of masculinity, and as a result has been classified as a rejection of masculinity. Traditional definitions of masculinity expect men to be "sturdy oaks", not particularly free in their expression of emotions, and to be emotionally independent. From the data, individuals began to emerge who were focusing on the friendship/commitment aspect in their profiles. Not to say that seeking friendship is unmasculine, but to be seeking friendship on a same sex oriented site appears to be rejecting the expectations of that website, those expectations being that men are to be online for sex. Indeed, several profiles mentioned a disdain for anyone looking for friendship on the website, often citing the phrase "This is ManHunt, not FriendHunt.”

Approximately $50.4 \%$ of the profiles were interested in friends, $10.0 \%$ were interested in social or personal attributes of the person (for example, if they liked movies or taking walks, and whether they were caring or understanding), and $31.5 \%$ were interested in dating. It is important to note that these results may be somewhat skewed. Often in the myriad of sexual interests each person indicated on their profile, they had also indicated they were searching for friendship and 
dating. It appeared to be counterintuitive; several profile indicated they were only looking or friendship yet included a profile picture of their genitals. Perhaps these men were simply selecting this interest because they were open to the possibility of friendship along with their desire for a hook up. I then filtered out the cases for ones that included no aspects of masculinity in order to better locate profiles that were focusing on friendship and dating only. Of the 110 profiles that did not include any of the four traits of masculinity, $40.9 \%$ were seeking friendship, $13.6 \%$ were searching for social or personal attributes in a man, and $19.1 \%$ were interested in dating. So while the numbers are small, there is a group of men who are using a sex oriented site as a venue to locate friendship and/or possible companionship. Two narratives below are excellent examples of how men are portraying themselves using no traits of masculinity:

\footnotetext{
"Easy going, simple tastes, not into the bar/club scene, once religious now spiritual, HIV negative, INFJ(?). I enjoy reading, music (especially R\&B and jazz but I love the 80s stuff, too), language study, gardening, or just hoping in the car for a drive."
}

"I'm always up for sparkling conversation and meeting charming gents. I'm a Midwest transplant whose interests include museum hopping, Victorian art, color science, running, photography, graphic design, fly-fishing, donut lust, old school gaming systems and general dorkery. Ideally, you should be around my age, enthusiastic, passionate, sincere, and not afraid to replace conjunctions with semicolons. Friends would be great. Something more would even be better."

The narratives above offer no indication that the individuals are concerned with finding a

hook up. The first profile offers his social and personal traits (enjoys jazz, gardening, and studying language) and mentions his distaste for the bar/club scene. He is offering his partner a detour from the supposed club scene that gay men are expected to take part in. The second profile goes into detail about how he likes to spend his free time, and even pokes fun when he claims to enjoy "donut lust" and "general dorkery." While some of the profiles specifically said they were not looking for hook ups, most simply chose not to mention sex at all in their profile, presumably feeling that describing themselves without any reference to sex would be enough to make their intention for companionship clear. The second profile mentions that friends would be 
great, but that he is ultimately interested in "something more", most likely a committed relationship.

The men who focus exclusively on friendship and dating appear to be those who are rejecting the expectation of masculinity altogether. The men in this subgroup have not exhibited any of the four main aspects of masculinity described in the previous section. The men focusing on masculinity would often indicate more than one aspect in their profile, such as sexual risk and penis size. Only $7.7 \%$ of the 480 profiles contained all four aspects of masculinity, while $22.9 \%$ of profiles contained none of the aspects. This disparity should be interpreted with caution because although there is a larger number of profiles void of the masculine aspects, it does not mean they automatically contain friendship and/or dating interests as some profiles contained no information at all, aside from age. Yet, it is interesting to see that on a website that apparently focuses on sex and masculinity, there is a substantial group of men who are rejecting this notion completely and are using the website to suit their needs.

\section{Age and Location Differences of the Traits}

Two of my objectives were to determine if age and location had any effect on the prevalence of the traits found in the profiles. In Appendix B is a chart with the percentage break down and significance levels for the four masculine traits and the four traits of negotiation and rejection of masculinity across age groups and location. In addition, percentages were also given for profiles that contained all four masculine traits, none of the masculine traits, all four of the rejection or negotiation traits, and profiles that contained none of the rejection or negotiation traits. 
The project was originally intended to explore the influence of location on the amount and type of information that was included in the profiles. A few weeks before I had decided to pursue this study, I began to note that profiles from rural areas tended to provide less information than profiles from larger cities. I had originally attributed this to the studies that indicated the conservative nature of most rural areas which placed a stigma on gay people and forced them to be secretive about their true identity. However, the results yielded a different reason for this outcome. It appears that the larger more diverse populations, sexually liberated atmosphere and constant bombardment of sexually charged advertisements often associated with larger urban cities may contribute to the individual being more open in his sexual explorations.

Of the 240 profiles from an urban area, $31.3 \% \%$ of these portrayed virility $\left(X^{2}=6.199\right.$, $\mathrm{df}=1, \mathrm{p}<.05)$ and $65.4 \%$ mentioned emotional detachment $\left(\mathrm{X}^{2}=5.018, \mathrm{df}=1, \mathrm{p}<.05\right) . \mathrm{I}$ believe that in an urban area, there is more men and as a result more competition among the men, thus the reason to focus on indicating the individual's penis size. Emotional detachment runs high I believe in urban settings because of the fast paced life of urban settings, possibly transferring over into the partner's sex life. Of the 240 urban profiles $6.7 \%$ identified as submissive individuals $\left(\mathrm{X}^{2}=7.513, \mathrm{df}=1, \mathrm{p}<.01\right)$ and $40.8 \%$ sought safe sex $\left(\mathrm{X}^{2}=1.179, \mathrm{df}=\right.$ $1, \mathrm{p}<.01)$. Safer sex may be more prevalent in urban areas because often urban areas have more education when it comes to safe sex. The only area that rural was significant in was the number of profiles that contained no rejecting or negotiating masculinity traits. Approximately $32.5 \%$ of the 240 rural profiles were void of rejecting or negotiating masculine traits $\left(X^{2}=7.728, d f=1, p\right.$ $<.01)$. A possible explanation for this is that men in rural settings would not be willing to focus on traits that were in contrast to masculinity since many aspects of masculinity are associated with the other men in rural settings. 
Of the 211 profiles that fell in the middle age group (30-45) $42.7 \%$ portrayed risk $\left(\mathrm{X}^{2}=\right.$ $10.849, \mathrm{df}=2, \mathrm{p}<.01)$. I reasoned that because men at this age consider themselves close to the threshold of "older" in the gay community, and thus they may be more willing to take sexual risks while they (and the younger gay men) still view them as youthful.

Of the 92 profiles that were classified as the older age group (46 and above) $67.8 \%$ portrayed emotional detachment $\left(\mathrm{X}^{2}=19.351, \mathrm{df}=2, \mathrm{p}<.001\right)$ and $53.3 \%$ portrayed strength $\left(\mathrm{X}^{2}\right.$ $=19.179, \mathrm{df}=2, \mathrm{p}<.001)$. I believe that older men are more focused on masculine traits as a way to combat their age which by gay culture may be seen as a hindrance. If masculinity is held in high regards by gay men then it stands to reason that older men will offer themselves as masculinity in order to better their chances of obtaining a hook up. Indeed, $15.2 \%$ of the older men's profiles contained all four traits of masculinity $\left(X^{2}=9.416, \mathrm{df}=2, \mathrm{p}<.01\right)$. Another result that we must discuss is that $51.1 \%$ of the older men's profiles sought safe sex. I believe that because this age group would have experienced the AIDS epidemic of the 1980's they are more aware of the dangers posed by unsafe sex

The young group had the majority of profiles that were void of all masculine traits, $35.3 \%$ of 170 profiles $\left(\mathrm{X}^{2}=28.030, \mathrm{df}=2, \mathrm{p}<.001\right)$. The younger men in this study may not be as concerned with masculinity as are their older male counterparts. For the younger men in the study, perhaps they feel that their age may be more precious than a presentation of masculinity. Or it may be that the definitions of masculinity have changed over the years. What the older men have been raised to believe what masculinity is may differ from the younger men. Another instance of disparity between the older and young age groups is that older men place more emphasis on safe sex than the younger men. Several possibilities may be able to account for this. Younger gay men may not be as concerned with sexual risk as they did not experience the AIDS 
epidemic first hand and therefore may not fear it as much. Another explanation is that while older gay men grew up in a time where condom use was not as prevalent, younger gay men have grown up in a society where using a condom is generally the norm.

For the profiles that contained all four indicators masculinity, we cannot say they are more masculine, but rather that they are placing more emphasis on masculinity. Perhaps they themselves are trying to overcompensate for aspects in their lives that they feel discredit their masculinity and as a result must include several traits of masculinity in their profile. The fact the middle age group has indicated more traits in their profile, both in the traits that embody masculinity as well as the ones that appear to be alterations of masculinity may be due to the fact that men that age may have experienced more and therefore indicate more traits in their profile. While other older may have had a longer time to develop themselves, middle aged men are still seen as commodity and may not be ruled out as quickly as an older individual would be since studies have shown that gay men place emphasis on age. Therefore, middle aged men in this study are aware of the significance of age, and that since they see themselves coming closer to the old age group, they are trying to make themselves appear as desirable as they can.

The results of this study have shown that masculinity is indeed fluid and constantly changing. The men are aware of what is masculine, and through embodiment of or negotiation with, have created their own version of what it is to be masculine. While there were differences in the prevalence of traits based upon rural or urban location, I believe that the differences found between older and young gay men showcases the ability that masculinity possesses to change over time. Indeed, this may be evidence of a cohort effect that appears to be stronger than masculinity. While older gay men have grown up in a society that places a strong emphasis on 
dominant masculinity, it may be that younger gay men have been raised in a time where altering the traditional definition of masculinity is acceptable. 


\section{Chapter 7: Conclusion}

This study has looked at how men on the website ManHunt.net are portraying themselves in accordance with, or in negotiation of, what is ascribed by hegemonic masculinity. For the men that are following the traditional norms of masculinity, the four main aspects that emerged were risk, virility, strength and emotional detachment. The specific type of risk the men were associating with was the risk of STD infection from sexual intercourse. While studies have indicated that engaging in risky behaviors is a part of affirming one's masculinity, some of the men in the study appear to be focused on the end result of danger and not just flirting with risk. Though bug chasers and "poz seeking sex" is a small group of men, it brings into question how far men will go in the realm of risk.

Most men of course do not seek this direct involvement with danger, and employ risk management practices that allow them to get as close to the danger as possible without actually contracting the virus. A traditional view of risky behaviors between men includes fighting or drag racing, while others are health related behaviors such as smoking, drinking and drug use. While most understand the risk associated with such activities, it is not always guaranteed that the individual will wreck his car while racing or develop cancer from smoking. Yet it appears that this small group of men is attempting to remove the ambiguity of risk and tailor their behaviors in order to find the infection and bring it into their bodies. It brings into question if these men are attempting to enact an accelerated or hyper form of masculinity, or if masculinity has no influence on their decision to contract the virus but rather results from cultural factors such as brotherhood or AIDS fatigue.

This result may speak generally for men as well. Men often seek risk as a way to validate their masculinity, some going further than others. It may be possible that compared to 
heterosexual men, gay men feel more of a need to achieve masculinity and thus will employ more active risk taking endeavors. It seems that there may be a competition among straight men and gay men in who takes the biggest risk. Perhaps gay men have for so long been deemed less of a man or weak, so as a way to correct this, have sought to pursue risk to the fullest extent.

Society has placed a large emphasis on how men should act, and one well known idea is that some men are measured by the size of their penis. There is a huge market dedicated to male enhancement and correcting erectile dysfunction and this market extends both into the heterosexual culture as well as the homosexual culture. The profiles act as an advertisement for the men, and it is the first thing their potential hook up will notice about the person. The fact that more than one-fifth of the profiles indicated their penis size shows that the men on this site view this as an important selling factor. I have often heard jokes among fellow gay men of certain individuals being labeled as "size queens" or having a large affinity for large penises. This anecdotal tidbit combined with the statistical data shows that being well endowed is a virtue for these men. Since the majority of men on the site are interested in hooking up, it appears that a large penis may overshadow other negatively viewed qualities and thus help that person appear more desirable to the audience. The results support the literature's claim that the measure of a man can often be decided by the measure of his member. The size of a man's penis may be a way to combat his other qualities that appear in contrast to masculinity. Though developing skills at sports takes practice and time, possessing a large penis from birth may be a way to overshadow the lack of practice.

Often the term masculinity conjures up images of strong, rugged men; indeed, we found that the concept of strength emerged from the data in this study. While the men in this study may not be lumberjacks or steel workers, they portrayed themselves to be strong in different facets. 
Physical strength was often desirable, seen with the men focusing on the gym bodies, yet it was also the strength associated with building and fixing a home or car and the strength associated with being a man's man. Since homosexuality is considered by traditional views to be incompatible with masculinity, these men have challenged this notion by describing themselves as "just one of the boys." The aesthetic nature of being a "regular Joe" has been documented in studies on gay culture as something desired, yet I believe that the men are also employing the concept of strength to rebel against the notion that someone who has sex with other men is automatically less of a man.

Emotional detachment served several purposes for the men in the study. The main reason was because men on the site saw sex as something impersonal yet passionate. By placing emotions on the hook up, it ceases to become the heightened sexual romp between two men and becomes something more feminine, something that the men here are attempting to distance themselves from. The other man (or men in some cases) in the sexual interaction is perhaps a vehicle for some to find sexual release, and the vehicle losses its potential when it is full of emotion. A second purpose is because some of the men were seeking to keep their sexual encounters secret, and developing emotional attachments would jeopardize the secrecy. I argue that the men who focus on emotional detachment view this as a way for them to retain their masculinity and perhaps battle against their internalized homophobia. If the men see their sexual encounter as purely sexual and void of emotional attachment, then perhaps they will not begin to think of themselves as actually gay.

The negotiations and rejection of masculinity show that some men are choosing not to follow the ideals of traditional hegemonic masculinity. The men who identify as submissive (sexually at least) are challenging the notion that submissive is synonymous with passive by 
requiring their sexual partner to perform certain and verbal actions. Simply being receptive during anal intercourse does not make these men believe they are in less control. Masculinity is not something that is fixed, but rather fluid and this is an excellent example of how the men are still embodying masculinity by being in control of the sexual encounter. Even degrading behavior such as licking his partner's boots or being urinated on are still specific requests and thus allow the submissive partner to remain in control.

Traditional masculinity holds the view that men should hold little regard for bodily safety, as seen with the aspect of risk, yet the men in this study have shown that they are able to engage in risk to affirm their masculinity yet still maintain a degree of bodily maintenance. The men are aware of the sexually transmitted diseases that exist in their community, and have adapted their actions to accommodate both risky sexual practices and a degree of managing that risk. Seeking friendship or companionship stands in stark contrast to how traditional masculinity says men should act, yet some of the men appear not to care. For them, masculinity appears to be a distant concern, if one at all. Studies have shown that heterosexual men who are unable to achieve masculinity often experience a level of stress from societal pressures. However, it seems these men are not experiencing this stress, and if they are, they are seeking other like minded individuals since minority stress can be alleviated by interacting with other similar individuals.

The disparity between the age of the individuals and the prevalence of the traits speaks to a cohort effect that exists on the population. Today, the safe sex campaign is everywhere, so one would expect the young gay men in the study to include safe sex in their profiles, yet this appears to not be the case. It may be that younger gay men understand that safe sex is the norm so they feel it is not necessary to include that trait in their profiles. It may also be that due to the advances in medicine and in the treatment of HIV/AIDS that younger gay men do not perceive 
the risk of HIV/AIDS as do their older male counterparts. It is also interesting to note that of the profiles which contained no traits of masculinity, the majority were in the younger age group. This appears to indicate that younger gay men are not as concerned with masculinity. They may feel that their age is more precious than appearing to be rugged or straight acting. However, the majority of profiles that contained all of the masculine traits were in the older age group. Youth is evaluated more harshly in the gay community than in the heterosexual one, and as a result it appears that older men are portraying themselves as masculine to appear desirable to other men.

Essentially, the online community under study was a virtual meat market. Men would access the site with certain goods (their portrayed masculinity) in an attempt to procure other goods (hooking up). While I had assumed this market place was the same for all who entered, it appears that the market place has changed for the younger gay men since they are displaying different traits than the older gay men. It appears that what are considered desirable goods depends on the people involved in the transaction. The exchange theory says people will attempt to obtain something by offering something in return. I feel that an addendum should be added that the exchange can be influenced by different factors within the same market place. For the older gay man who desires a hook up, he may believe that his strength and rugged persona may be considered top-notch, but the younger gay man offers his age as a prized possession.

What should also be considered when examining a transaction with the general exchange theory are the parties involved. While this study did not investigate it, it is important to know who is seeking who in the market place. For example, if the older men feel their masculinity is valued, do they offer it to other older men who value the same? Or are they marketing themselves as something desired for the youth since it appears the youth does not come to the table offering the same thing. 
The results of the study speak mostly to the concept of sexuality and masculinity and the fluid nature of both. What was previously defined about masculinity not only changes over time but from person to person as well. We have seen that not only do the gay men take their masculinity from what is ascribed to hegemonic masculinity, but they have also used their own definitions to define their actions that by conventional standards would be seen as unmasculine. Another result to consider from the research is the idea of gender and sexuality being a two-way street. Traditionally, people have believed that sex influences gender; that our sexuality directs our gendered performance. My study has shown that this is not a unidirectional process but rather that gender can influence sexuality. The gender roles of masculine and feminine have come into question with regards to their susceptibility to the influence of sex. The men in this study have shown that a masculine individual can perform the sexuality of a supposed feminine individual and not void his masculinity. Gender is something that is performed through repeated actions, and those repeated actions in sexuality have disrupted the rigid and unidirectional nature of sexuality and gender.

We must keep in mind that this exploratory analysis cannot be generalized to the larger gay population. While I found that men on this site are constructing a presentation of masculinity using aspects of hegemonic masculinity, other gay men may not be engaged in the same process. Many gay men may identify themselves as more feminine than masculine. Another reason that the results cannot speak for the greater gay population is that not all gay men use the Internet for sex. In larger urban areas, gay communities are more active and thus allow for better networking through the community so that a web-based hook up site may not be necessary or even desired. While the topic of masculinity is very broad, the scope of this research is rather narrow; the study looks at men, who use the Internet, for the purposed of hooking up, on ManHunt.net. I have 
already acknowledged that even within the small group of gay men who use online hook up sites; there exists diversity because different websites are geared towards different individuals. Manhunt.net is a general hook up site, but some sites are dedicated to body building men (BigMuscle.com) while other sites are even more specific (BigMuscleBear.com).

A possible limitation may be from the nature of the data itself; we have to take what the men indicate in their profile at face value. However, since this is a study of what the men are presenting about themselves and not what they actually are, the analysis of the presentation in and of itself is sufficient. While having a second coder to produce a measure of inter-coder reliability would lend more credit to the results, the codebook that was used to code the profiles is direct and rather concise. Coding for many of the traits required little interpretation and more direct observation. The other traits that did require interpretation (such as portraying themselves as a bear) were described in the codebook and based on previous research. The narratives provide qualitative data to support how the men are portraying their aspects of masculinity, but because the narratives were self-selected by myself this does present a limitation.

Further studies could explore this portrayal of masculinity by directly interviewing the men. This study looked at self-presentation but it would be of interest to see if the men felt that the interpretation of their narratives was accurate. A man could have described something about himself in the profile for a completely different reason than was perceived. From these interviews, it may be possible to compare and contrast how the men portray themselves online to how they carry themselves in everyday life. A man who describes his self as dominant and aggressive in the profile may actually be rather timid to his friends and coworkers. The interviews could also shed light on how important masculinity is to their entire personal identity. 
This study has shown that men are engaged both in the pursuit of and negotiation with masculinity. Heterosexual and homosexual men face different social pressures and this may result in a different approach to masculinity for each group. One of the main "requirements" for masculinity is heterosexuality. Straight males at times must prove their "straightness" through a variety of activities but it seems for the men in this study, they are proving their "straightness" in different ways and for different reasons. While heterosexual males may try to prove their straightness in order to be equal with other straight men, some of the men in this study are focusing on acting straight for purely aesthetic purposes. Rejecting masculinity may not produce the same stress in gay men that is supposedly does for straight men. While no interviews were conducted in this study, the profiles of the men who rejected the aspects of masculinity appeared to be content with their personality by the light and conversational tone in their profiles. Perhaps because society may view gay men as those who cannot obtain masculinity, gay men may feel they are not held to the same rigid standards as straight men. The men in this study have shown that masculinity is not something fixed by any means, at that at any given time for any given person, that definition of masculinity can be altered, and changed, or obliterated altogether. 


\section{$\underline{\text { References }}$}

Adler, Alfred. 1928. ed. F. Kobler. "Psychologie der Macht." Gewalt und Gewaltlosigkeit. Zurich: Rotapfelverlag.

Altman, Dennis. 1972. Homosexual: Oppression and Liberation. Sydney: Angus \& Roberston.

Bailey, Michael, Peggy Kim, Alex Hills, and Joan Linsenmeier. 1997. "Butch, Femme, or Straight Acting? Partner Preferences of Gay Men and Lesbians." Journal of Personality and Social Psychology. 73(5):960-973.

Barker, Judith. 2004. "Lesbian Aging: An Agenda for Social Research.” Pp. 31-70 in Gay and Lesbian Aging: Research and Future Directions, edited by Gil Herdt and Brian De Vries. New York: Springer Publishing.

Bersani, Leo. 1995. Homos. Cambridge: Harvard University Press.

Bird, Sharon R. 1996. "Welcome to the Men's Club: Homosociality and the Maintenance of Hegemonic Masculinity." Gender \& Society. 10(2):120-32.

Blazina, Chris and Edwards Watkins. 1996. "Masculine and Gender Role Conflict: Effect on College Men's Psychological Well-Being, Chemical Substance Usage, and Attitudes Towards Help-Seeking.” Journal of Counseling Psychology. 43:461-465.

Bly, Robert. 1990. Iron John: A Book about Men. Reading, MA: Addison-Wesley.

Brannon, Robert. 1976. “The Male Sex Role- and What It's Done for Us Lately.” Pp. 1-40 in The Forty-Nine Percent Majority, edited by Robert Brannon and Deborah David. Reading, MA: Addison-Weseley.

Brannon, Robert and Samuel Juni. 1984. "A Scale for Measuring Attitudes about Masculinity." Psychological Documents. 14:6-7.

Brittan, Arthur. 1989. Masculinity and Power. New York: Basil Blackwell Inc.

Brod, Harry, ed. 1987. The Making of Masculinities: The New Men's Studies. Boston: Allen and Unwin.

Bunton, Robin and Paul Crawshaw. 2002. "Risk, Ritual and Ambivalence in Men's Lifestyle Magazines." Pp. 187-203 in The Commodification of Health Care, edited by Saras Henderson and Alan Peterson. London: Routledge.

Butler, Judith, ed. 1999. Gender Trouble: Feminism and the Subversion of Identity. New York: Routledge. 
Centers for Disease Control and Prevention. 2010. "Basic Information about HIV and AIDS." CDC. Retrieved July 29, 2010 (http://www.cdc.gov/hiv/topics/basic/)

Chodorow, Nancy. 1978. The Reproduction of Mothering: Psychoanalysis and the Sociology of Gender. Berkley: University of California Press.

Clarkson, Jay. 2006. “'Everyday Joe' versus "Pissy, Bitchy, Queens": Gay Masculinity on Straightacting.com.” The Journal of Men's Studies. 14(2):191-207.

Colebrook, Claire. 2004. Transition: Gender. Hampshire: Palgrave Macmillan.

Connell, Raewyn W. 1992. "A Very Straight Gay: Masculinity, Homosexual Experience, and the Dynamic of Gender.” American Sociological Review. 57(6):735-751.

Connell, Raewyn W. 1995. Masculinities. Berkley: University of California Press.

Courtenay, Will H. 2001. "Constructions of Masculinity and their Influence on Men's WellBeing: A Theory of Gender and Health." Social Science \& Medicine. 50:1385-1401.

D’Emilio, John. 1983. "Capitalism and Gay Identity.” Pp 100-113 in Powers of Desire: The Politics of Sexuality, edited by Ann Snitow, Christine Stansell, and Sharan Thompson. New York: Monthly Review Press.

Duck, Waverly. 2009. "Black Male Avoidance of HIV/AIDS Testing as a Masculine Health Practice." Journal of African American Studies. 13:282-306.

Edwards, Tim. 1994. Erotics \& Politics: Gay Male Sexuality, Masculinity, and Feminism. New York: Routledge.

Epel, Elissa, Alexandra Spanakos, Julia Kasl-Godley, and Kelly Brownwell. 1996. "Body Shape Ideals Across Gender, Sexual Orientation, Socioeconomic Status, Race and Age in Personal Advertisements." Journal of Eating Disorders. 19(3):264-273.

Forrester, DA. 1986. "Myths of Masculinity". Nursing Clinics of North America. 21:15-23.

Glaser, Barney and Anselm Strauss. (1967). "The Discovery of Grounded Theory: Strategies for Qualitative Research.” Chicago: Aldine.

Goffman, Erving. 1959. Presentation of Self in Everyday Life. Garden City NY: Doubleday Anchor Books.

Goltz, Dustin B. 2007. "Laughing at Absence: Instinct Magazine and the Hyper-Masculine Gay Future?" Western Journal of Communication. 71(2):93-113.

Gudelunas, David. 2005. "Online Personal Ads: Community and Sex, Virtually.” Journal of Homosexuality. 49(1):1-33. 
Halkitis, Perry. 2001. "An Exploration of Perceptions of Masculinity among Gay Men Living with HIV.” Journal of Men's Studies. 9(3):413-429.

Halkitis, Perry and Jeffrey Parsons. 2003. "Intentional Unsafe Sex (Barebacking) among HIVPositive Gay Men who Seek Sexual Partners on the Internet.” AIDS Care. 15(3):367-378.

Hamilton, Christopher and James Mahalik. 2009. "Minority Stress, Masculinity and Social Norms Predicting Gay Men's Health Risk Behaviors.” Journal of Counseling Psychology. 56(1):132-141.

Harry, Beth, Keith Sturges, and Janette Klinger. 2005. "Mapping the Process: An Exemplar of Process and Challenge in Grounded Theory Analysis." Educational Researcher 34(2):313.

Hatala, Mark N., Katherine Milewski, and Daniel Baack. 1999. "Dowloading Love: A Content Analysis of Internet Personal Advertisements Placed by College Students." College Student Journal. 33(1):124-130.

Healy, Murray. 1996. Gay Skins: Class, Masculinity and Queer Appropriation. London: Cassell.

Hennen, Peter. 2005. "Bear Bodies, Bear Masculinity". Gender \& Society. 19(1):25-43.

Herdt, Gilbert. 1997. Same Sex Different Cultures: Exploring Gay and Lesbian Lives. Boulder, CO: Westview Press.

Holme, Dave, Patrick O'Byrne, Denise Gastaldo, and Anthony Lombardo. 2008. "Bareback Sex: A Conflation of Risk and Masculinity." International Journal of Men's Health. 7(2):171191.

Hostetler, Andrew. 2004. "Old, Gay and Alone? The Ecology of Well-Being among MiddleAged and Older Single Gay Men.” Pp. 143-162 in Gay and Lesbian Aging: Research and Future Directions, edited by Gil Herdt and Brian De Vries. New York: Springer Publishing.

Keen, Sam. 1991. Fire in the Belly: On Being a Man. New York: Bantam.

Kendall, Christopher. 2004. "Educating Gay Male Youth: Since When is Pornography a Path Towards Self-Respect.” Journal of Homosexuality. 47(3):83-128.

Kervin, Denise. 1991. "Gender Ideology in Television Commercials.” Pp. 235-256 in Television Criticism: Approaches and Applications, edited by Leah Vande Berg and Lawrence Wenner. New York: Longman.

Kimmel, Michael S., ed. 1987. Changing Men: New Directions in Research on Men and Masculinity. Newbury Park, CA: Sage. 
Kimmel, Michael and Michael Messner, eds. 1989. "Men as Gendered Beings." Pp. 187-233 in Men's Lives, edited by Michael Kimmel and Michael Messner. New York: Pearson.

Kimmel, Michael S. 1994. "Masculinity as Homophobia: Fear, Shame, and Silence in the Construction of Gender Identity." Pp. 119-141 in Theorizing Masculinities, edited by Harry Brod and Michael Kaufman. London: Sage.

Kimmel, Michael. 2008. Guyland. New York: HarperCollins Publisher.

Lee, John. 1976. "Forbidden Colors of Love: Patterns of Gay Love and Gay Liberation.” Journal of Homosexuality. 1(4):401-418.

Lewis, Glen. 1983. Real Men Like Violence. Sydney: Kangaroo Press.

Long, Ron. 1997. "The Fitness of the Gym." Harvard Gay and Lesbian Review. 4(3):20-23.

Lumby, Malcom. 1978. "Men Who Advertise for Sex.” Journal of Homosexuality. 4(1):63-72.

Manago, Adriana, Michael Graham, Patricia Greenfield, and Goldie Salimkhan. 2008. "Self Presentation and Gender on MySpace." Journal of Applied Developmental Psychology. 29(6):446-458.

Maskowitz, David and Michael Roloff. 2007. "The Ultimate High: Sexual Addiction and the Bug Chasing Phenomenon.: Sexual Addiction \& Compulsivity. 14(1):21-40.

Mieli, Mario, ed. 1980. Homosexuality and Liberation: Elements of Gay Critique. London: Gay Men's Press.

Neuendorf, Kimberly A. 2003. The Content Analysis Guidebook. Thousand Oaks, CA: Sage Publishing.

Nugteren, Helena M., G.T. Balkema, A.L. Pascal, W.C.M. Schultz, J.M. Nijman, and M.F. van Driel. 2010. "18 Year Experience in the Management of Men with a Complaint of a Small Penis." Journal of Sex \& Marital Therapy. 36(2):109-117.

Okie, Susan. 2000. "When Virtual Contact Becomes Real Contact.” The Washington Post. July 26, p. A2.

Parker, Holt N. 2001. "The Myth of the Heterosexuality: Anthropology and Sexuality for Classicists.” Arethusa. 34:313-362.

Phau, Voon C., Desiree Ciambrone, and Obed Vazquez. 2009. "Advertising Health Status in Male Sex Worker's Online Ads.” The Journal of Men's Studies. 17(3):251-258. 
Pleck, Joseph H., Freya Sonenstein, and Leighton Ku. 1994. "Problem Behaviors and Masculinity Ideology in Adolescent Males.” Pp. 165-186 in Adolescent Problem Behaviors: Issues and Research, edited by Robert Ketterlinus and Michael. Hillsdale, NJ: Erlbaum.

Preston, Deborah B., Anthony D’Augelli, Cathy Kassab, Richard Cain, Frederick Schulze, and Michael Starks. 2004. "The Influence of Stigma on the Sexual Risk Behavior of Rural Men Who Have Sex with Men.” AIDS Education and Prevention. 16(4):291-303.

Rofes, Eric. 1997. "Academics as Bears: Thoughts on Middle-Class Eroticisation of Workingmen's Bodies." Pp. 89-99 in The Bear Book: Readings in the History and Evolution of a Gay Male Subculture, edited by Les Wright. NewYork: Harrington Press.

Reige-Laner, Marry and Levi Kamel. 1977. “Media Mating I: Newspaper 'Personals' Ads of Homosexual Men.” Journal of Homosexuality. 4(1):41-61.

Rheingold, Howard. 1993. The Virtual Community: Homesteading on the Electric Frontier. Reading, MA: Addison-Wesley.

Simpson, Mark. 1994. Male Impersonators. London: Cassell.

Smith, Anthony. 2000. “'Safety' in Gay Men's Personal Ads, 1985-1996." Journal of Homosexuality. 39(1):43-48.

Thompson, Edward and Joseph Pleck. 1986. "The Structure of Male Role Norms." American Behavioral Scientist. 29:531-543

Thayer, Alexander, Marry Evans, Alicia McBride, Matt Queen, and Jan Spyridakis. 2007. "Content Analysis as a Best Practice in Technical Communication Research." Journal of Technical Writing and Communication. 37(3):267-279.

Tolson, Andrew. 1977. The Limits of Masculinity. London: Tavistock.

Turkle, Sherry. 1995. Life on the Screen: Identity in the Age of the Internet. London: Weidenfield \& Nicholson.

Wegesin, Domonick and Heino Meyer-Bahlburg. 2000. "Top/Bottom Self-Label, Anal Sex, HIV Risk and Gender Role Identity in Gay Men in New York City." Journal of Psychology \& Human Sexuality. 12:43-62.

Westermarck, Edward. 1908. The Origin and Development of the Moral Ideas, Vol. 2. London: Macmillan and Co.

Woodland, Randal. 2000. "Queer Spaces, Modem Boys and Pagan Statues: Gay/Lesbian Identity and the Construction of Cyberspace." Pp. 403-415 in The Cyberspace Reader, edited by David Bell and Barbara Kennedy. New York: Routledge. 


\section{Appendix A}

\begin{tabular}{|c|c|c|}
\hline Traits & Portrayed & Sought \\
\hline \multicolumn{3}{|l|}{ ASPECTS OF MASCULINITY } \\
\hline $\begin{array}{l}\text { RISK: Sexual Risk (Interests associated with STDs } \\
\text { infection i.e. fisting) }\end{array}$ & $36.3 \%$ & N/A \\
\hline VIRILITY: Penis Size (Size of the person’s penis) & $26.3 \%$ & $1.9 \%$ \\
\hline $\begin{array}{l}\text { STRENGTH: Body Boasting (Gym body, muscles, } \\
\text { physically fit, etc); Outdoors (Interested in hiking, camping, etc.); } \\
\text { Regular (Being an "average Joe”, being laid-back, etc.); Bear } \\
\text { (Being hairy, older, "chubby," etc.); Jock (Being athletic, playing } \\
\text { sports) }\end{array}$ & $37.5 \%$ & $1.3 \%$ \\
\hline $\begin{array}{l}\text { EMOTIONAL DETACHMENT: NSA (Seeking no strings attached } \\
\text { hook up) }\end{array}$ & N/A & $60.4 \%$ \\
\hline \multicolumn{3}{|l|}{ NEGOTIATIONS AND REJECTION OF MASCULINITY } \\
\hline $\begin{array}{l}\text { STRAIGHT SEEKING: Straight/Bisexual (Being and/or acting } \\
\text { straight or bisexual) }\end{array}$ & $9.6 \%$ & $24.4 \%$ \\
\hline SAFE SEX: Safe Sex (Seeking safe sex) & N/A & $31.5 \%$ \\
\hline $\begin{array}{l}\text { BEING SUBMISSIVE: Submissive (Submissive qualities i.e. } \\
\text { "being used") }\end{array}$ & $4.2 \%$ & $0.8 \%$ \\
\hline $\begin{array}{l}\text { SEEKING FRIENDSHIP/COMMITMENT: Seeking friends, } \\
\text { dating, social/personal attributes (hobbies, personality) }\end{array}$ & N/A & $58.9 \%$ \\
\hline
\end{tabular}

Percentages of the masculine traits and the negotiation/rejection traits. 


\section{Appendix B}

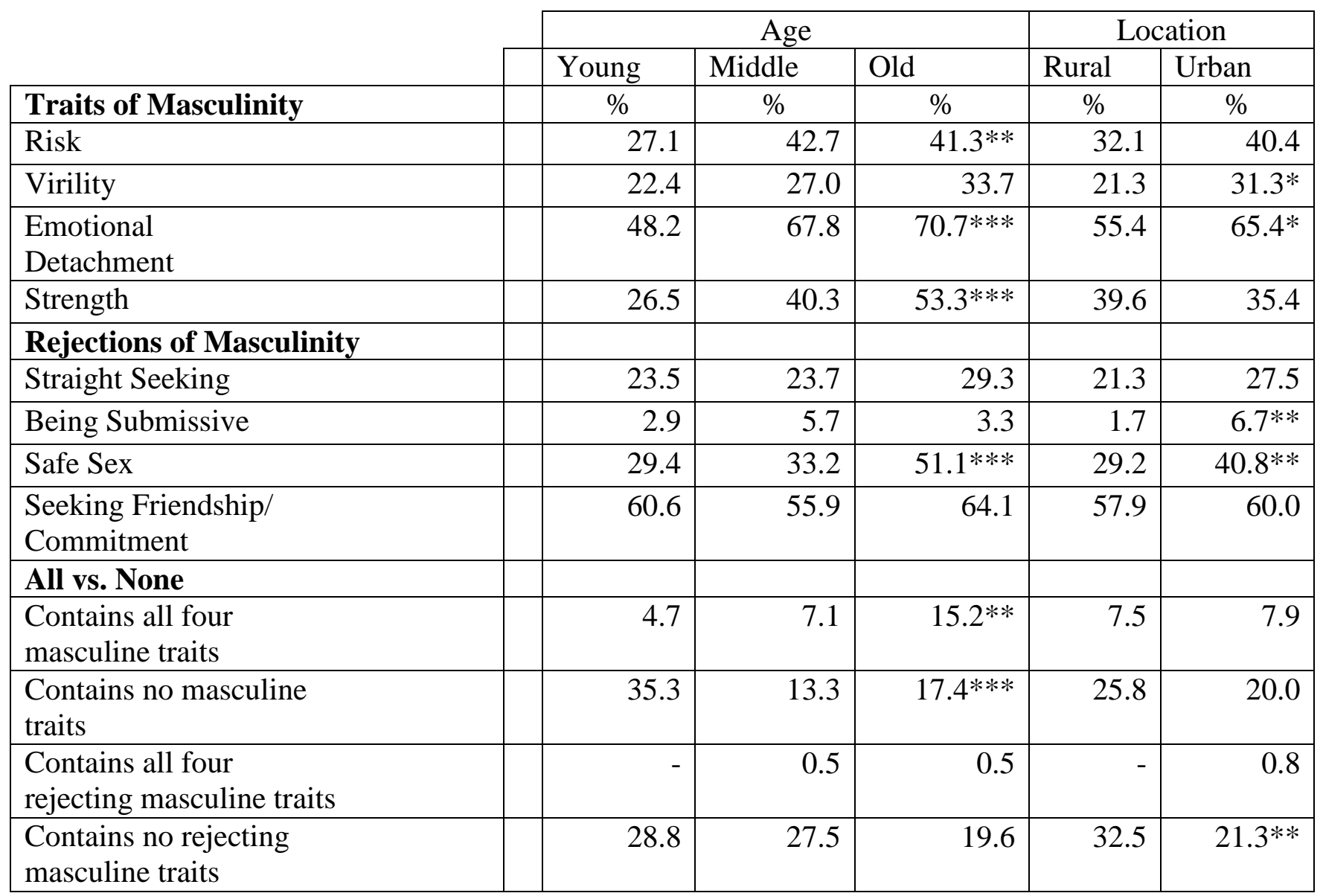

Percentage breakdowns across age group and location.

The age groups are: young (18-29), middle (30-45), old (46 and above).

$* \mathrm{p}<.05, * * \mathrm{p}<.01, * * * \mathrm{p}<.001$. 


\section{Appendix C}

\section{Codebook}

ADNUMBER

Number assigned to each profile within the state of the profile

CITY

City in which the person resides

STATE

State in which the person resides

\section{REGION}

Region which the person resides, determined by regional divisions used by the United States Census Bureau

$\begin{array}{ll}1 & \text { Northeast } \\ 2 & \text { Midwest } \\ 3 & \text { South } \\ 4 & \text { West }\end{array}$

\section{DIVISION}

Division which the person resides, determined by regional divisions used by the United States Census Bureau

$\begin{array}{ll}1 & \text { New England } \\ 2 & \text { Mid-Atlantic } \\ 3 & \text { East North Central } \\ 4 & \text { West North Central } \\ 5 & \text { South Atlantic } \\ 6 & \text { East South Central } \\ 7 & \text { West South Central } \\ 8 & \text { Mountain } \\ 9 & \text { Pacific }\end{array}$

\section{RURALURBAN}

Whether the area the person is from fall into a rural or urban classification based on an integration of Rural Definition \#7 (All counties outside metropolitan areas in 2003 (based on 2000 census data) and Rural Definition \#8 (Census tracts with 2000 Rural-Urban Commuting Area codes 4 through 10)

$1 \quad$ Rural 
PROFILENAME

Name of the profile as it appears on the website

PICTURE

Description of the presence of absence of a profile picture

$0 \quad$ No picture

1 Picture, but locked to the public

2 Picture, shows face

3 Picture, shows body

4 Picture, shows genitals

5 Picture, multiple, shows genitals and/or face and/or body

SEXUALISED

Level of sexualization in photos

$0 \quad$ No picture

1 Not very sexual, body is clothed, normal stance

2 Sexual, nude photograph, provocative pose

\section{ETHNICITY}

Classification of the person's ethnicity

$0 \quad$ Ask me (or no information)

1 Asian

2 Black

3 Latino

$4 \quad$ Middle Eastern

5 Mixed

6 Native American

7 Other

8 South Asian

9 White

HIVSTATUS

Classification of the person's HIV status

$0 \quad$ No information

1 Don't know

2 Negative

3 Positive

4 Unanswered 


\author{
POSITION \\ Classification of the person's sexual position preference \\ $0 \quad$ No information \\ 1 Bottom \\ 2 Top \\ $3 \quad$ Versatile
}

\title{
RISK
}

Presence or absence of interest in risky sexual practices (those with increased chances of contracting STD/HIV such as swallowing ejaculatory fluid, UAI (unprotected anal intercourse), group sex, rough sex, fisting, etc.)

$0 \quad$ No information

1 Presence

\section{PENIS LENGTH}

Presence or absence of the person's penis length

$0 \quad$ No information

1 Presence

\section{BODY BOASTING}

Presence or absence of mentioning a gym body, possessing muscles, being physically fit, etc.

$0 \quad$ No information

1 Presence

\section{OUTDOORS}

Presence or absence of interesting in being outdoors, hiking, camping, etc.

$0 \quad$ No information

1 Presence

\section{REGUALR}

Presence or absence of mentioning being an "average Joe," being a "regular guy," being laidback, being "one of the guys," etc.

$0 \quad$ No information

1 Presence 
BEAR

Presence or absence of mentioning the qualities of bear culture suck as being stocky, being hairy, being chubby, etc.

$0 \quad$ No information

1 Presence

JOCK

Presence or absence of mentioning being athletic, interests in sports, etc.

$0 \quad$ No information

1 Presence

NSA

Presence or absence of seeking no strings attached sex.

$0 \quad$ No information

1 Presence

STRAIGHT SEEKING

Presence or absence of seeking individuals who are straight/bisexual.

$0 \quad$ No information

1 Presence

SAFE SEX

Presence or absence of seeking safe sex.

$0 \quad$ No information

1 Presence

SUBMISSIVE

Presence or absence of submissive qualities such as "being used" and other degrading practices.

$0 \quad$ No information

1 Presence

\section{FRIENDSHIP}

Presence or absence of seeking friendship.

$0 \quad$ No information

1 Presence 


\section{PERSONAL/SOCIAL ATTRIBUTES}

Presence or absence of seeking personality traits or social interests in other men.

$0 \quad$ No information

1 Presence

DATING

Presence or absence of seeking dating or long-term relationships.

$0 \quad$ No information

1 Presence 